\title{
MODELAGEM ECONÔMICA DE UMA INDÚSTRIA CERÂMICA ATRAVÉS DO SISTEMA DE APOIO À DECISÃO POC®
}

\section{ECONOMIC MODELING OF A CERAMIC MANUFACTURER THROUGH POC® DECISION SUPPORT SYSTEM}

\author{
Rochelly Sirremes Pinto ${ }^{1}$; Abraão Freires Saraiva Júnior ${ }^{2}$; Fábio Roberto Abreu Junior ${ }^{3}$; Raimundo \\ Alberto Rêgo Junior ${ }^{4}$; Reinaldo Pacheco da Costa ${ }^{5}$ \\ ${ }^{1}$ Universidade Federal do Rio Grande do Norte - UFRN \\ rochellykarillo@hotmail.com \\ ${ }^{2}$ Universidade Federal Ceará - UFC \\ abraaofsjr@gmail.com \\ ${ }^{3}$ Universidade Federal do Semi-Árido - UFERSA \\ f_jwnyor@hotmail.com \\ ${ }^{4}$ Universidade Federal do Semi-Árido - UFERSA \\ albertojuniorpdf@hotmail.com \\ ${ }^{5}$ Escola Politécnica da Universidade de São Paulo - POLI USP \\ rpcosta@usp.br
}

\begin{abstract}
Resumo
Atualmente, para se manter competitiva e auxiliar a tomada de decisão, uma organização deve fazer uso de tecnologias compatíveis com as necessidades de gestão econômica dos seus processos de negócios. Neste contexto, o artigo objetiva apresentar a utilização do sistema de apoio à decisão $P O C^{\circledR}$ - Preços, Orçamentos e Custos Industriais - na modelagem e na análise gerencial de custos e preços para tomada de decisões econômicas em uma indústria cerâmica. Para cumprir o objetivo, o artigo é trabalhado metodologicamente a partir de uma pesquisa bibliográfica e de uma pesquisa de campo em que são levantadas e analisadas as informações coletadas sobre o processo produtivo e sobre a estrutura de custos e preços dos produtos da indústria estudada. Como principais resultados, o sistema $P O C^{\circledR}$ possibilitou a modelagem econômica das operações para $(i)$ a construção dos diagramas de montagem dos produtos e da curva ABC de custos de materiais e de faturamento de produtos, e (ii) a determinação dos custos, das despesas, dos preços, das margens de contribuição dos produtos e do lucro da indústria estudada. Por fim, conclui-se que a utilização do sistema de apoio à decisão $P O C^{\circledR}$ mostrou-se útil para realizar a modelagem econômica das operações e auxiliar os gestores da indústria cerâmica abordada no estudo.
\end{abstract}

Palavras-chave: modelagem econômica de operações; sistema de apoio à decisão POC $^{\circledR}$; gestão de custos e preços; indústria cerâmica.

\section{Introdução}

A indústria de cerâmica é uma das mais antigas da humanidade e os produtos cerâmicos tornaram-se, ao longo da história, essenciais para o desenvolvimento das civilizações. No Brasil, o 
setor de cerâmica cresce a cada dia devido ao aumento populacional e, consequentemente, ao aumento do consumo dos produtos advindos desse setor. $\mathrm{O}$ fator determinante para a localização das indústrias ceramistas é, principalmente, a disponibilidade de matéria-prima, ou seja, a argila (ANICER, 2014). O Rio Grande do Norte é um dos estados com maior produção no segmento de cerâmica vermelha brasileiro e o maior produtor de telhas do país, contando com 186 empresas em atividade, distribuídas em 42 municípios. No setor, predominam as micro e pequenas empresas. (SEBRAE-RN, 2014).

Hodiernamente, existem empresários que constituem empresas sem ter conhecimentos técnicos suficientes para realizarem uma análise de mercado ou, até mesmo, uma adequada análise econômico-financeira da empresa em que atua. Essa característica é acentuada quando são consideradas às micro e pequenas empresas brasileiras, em que a carência de profissionalização da gestão é recorrente (SEBRAE-SP, 2014). No setor ceramista norteriograndense, esse cenário não é diferente, inclusive, quando se consideram aspectos relacionados à análise gerencial de custos e de preços de vendas com vistas à modelagem econômica das operações do empreendimento para fins de tomada de decisão. Tal como indicam Atkinson et al (1997), Garisson et al (2006), Bornia (2010) e Martins (2010), uma adequada utilização de informações de custos e de preços para tomada de decisão é um importante aspecto para a gestão, eficiência e competitividade das organizações.

Dentre as várias ferramentas desenvolvidas para se trabalhar o tema "custos e preços", na perspectiva da contabilidade gerencial e direcionado às operações de manufatura, tem-se o sistema de apoio à decisão $\mathrm{POC}^{\circledR}$ - Preços, Orçamentos e Custos Industriais - desenvolvido por acadêmicos e profissionais ligados ao Departamento de Engenharia de Produção da Escola Politécnica da Universidade de São Paulo com o objetivo de realizar, de forma acurada e estruturada, várias análises quantitativas de apoio à tomada de decisões empresariais na perspectiva da gestão econômica de operações (COSTA; FERREIRA; SARAIVA JR., 2010). Neste contexto, o artigo objetiva apresentar a utilização do sistema de apoio à decisão $\mathrm{POC}^{\circledR}$ para auxiliar a modelagem e a análise gerencial de custos e preços para tomada de decisões econômicas em uma indústria de produtos cerâmicos do estado do Rio Grande do Norte.

Além da corrente introdução, o artigo é estruturado a partir de uma seção dedicada à metodologia utilizada no estudo. Em seguida, é exposta a fundamentação teórica em que são abordados os principais conceitos da Contabilidade Gerencial e da Engenharia de Produção, além das principais características inerentes ao sistema de apoio à decisão POC $^{\circledR}$. Na sequência, é apresentada a utilização do sistema $\mathrm{POC}^{\circledR}$ em vários aspectos da tomada de decisão que envolve a análise de custos e preços para a modelagem econômica de uma indústria do setor ceramista 
norteriograndense. Finalmente, são expostas as conclusões dos autores, as limitações do estudo e as recomendações para trabalhos futuros.

\section{Metodologia}

A metodologia aplicada foi constituída, primeiramente, a partir de pesquisas bibliográficas, que, conforme Gil (2002, p. 44), é desenvolvida com base em material já elaborado, constituído, principalmente, de livros e artigos. A pesquisa abordou temas inerentes aos campos da Contabilidade Gerencial e da Engenharia de Produção, especificamente, no que se refere a conceitos e técnicas relacionados à estruturação, à quantificação e à análise gerencial de custos e preços e que, ainda, pudessem ser utilizadas no contexto da modelagem econômica de operações industriais. Como resultados iniciais, obtiveram-se a compreensão conceitual e a escolha do POC $^{\circledR}$ como sistema de apoio a decisão a ser utilizado no estudo.

Munidos da estrutura teórica necessária, realizou-se uma pesquisa de campo. De acordo com Marconi e Lakatos (2011), entende-se como pesquisa de campo a observação de fatos e fenômenos tal como ocorrem espontaneamente, incluindo a coleta de dados a eles referentes e o registro de variáveis que se presumem relevantes, para analisar estes fenômenos. Para efeito da corrente pesquisa, realizou-se uma pesquisa de campo em uma empresa escolhida a partir de uma amostra não-probabilística unitária intencional, considerando o contexto do desenvolvimento do setor de cerâmica da região e o fácil acesso aos dados necessários para a realização do estudo. Desta forma, o universo da pesquisa foi uma empresa com atividade econômica industrial no setor de cerâmica estrutural do estado do Rio Grande do Norte.

$\mathrm{Na}$ execução da pesquisa de campo, foram realizadas visitas às instalações da empresa selecionada e, como instrumento de coleta de dados e informações, foram realizadas observações assistemáticas em equipe e entrevistas não-estruturadas, além de acessados arquivos eletrônicos e físicos da empresa. A partir das visitas técnicas in loco, foram realizadas medições de tempo, catalogadas as operações envolvidas no processo de manufatura e analisados os dados fornecidos pela gerência da organização a fỉm de estruturar as informações importantes para a operacionalização da modelagem econômica da indústria cerâmica através do sistema POC ${ }^{\circledR}$.

\subsection{Contabilidade de custos e contabilidade gerencial}

Chatfield (1971) e Horngren (2006) pontuam que, no período da Revolução Industrial, a contabilidade de custos era considerada mais útil como auxílio à racionalização da determinação de preços e à contabilização de estoques do que como ferramenta de controle gerencial. Com o passar do tempo, a contabilidade de custos passou a abordar também a geração de informações para fins fiscais e de controle sobre as operações de compra e venda das organizações. 
Na visão de Costa, Ferreira e Saraiva Jr. (2010), originalmente, a contabilidade de custos se referia às formas de acumular e aprovisionar os custos históricos aos produtos e departamentos com o objetivo de valorizar estoques e determinar a renda a ser tributada da empresa, confundindo-se com a contabilidade financeira. Entretanto, atualmente, a contabilidade de custos confunde-se com a contabilidade gerencial porque serve para múltiplos objetivos e diferentes situações de tomada de decisão gerencial. Em suma, de acordo com Martins (2010), a contabilidade de custos tem duas funções relevantes: o auxílio ao controle e a ajuda no processo de tomada de decisões. No contexto da vertente gerencial, a contabilidade de custos auxilia tanto na coleta de dados importantes e fundamentais para a realização dos mais diversos tipos de previsão, como também oferece informaçãoes relação à preços de vendas, decisões de mix de produtos, aquisição de novo maquinário, análise de lucratividade de produtos, clientes e pedidos, entre outros (PADOVEZE, 2006).

Os ramos na contabilidade e o uso destes variam de acordo com seus usuários e são distintos em relação às suas necessidades, perspectivas e expectativas de utilização das informações contábeis (FREZATTI; AGUIAR; GUERREIRO. 2007). No contexto de usuários externos tais como acionistas e orgãos fiscais, insere-se a contabilidade financeira. Já no contexto de usuários internos da organização, insere-se a contabilidade gerencial (HANSEN e MOWEN, 1997). Na contabilidade gerencial, o processo de identificação, mensuração, acumulação, análise, preparação, interpretação e comunicação das informações deve ser direcionado pelas necessidades informacionais dos indivíduos internos da empresa e deve orientar as decisões operacionais e de investimentos (ATKINSON et al, 1997), além de auxiliar os gestores na formulação e na implementação da estratégia de uma organização (IMA, 2008). Neste sentido, dentro da perspectiva da contabilidade gerencial, insere-se o sistema de apoio à decisão $\mathrm{POC}^{\circledR}$ abordado a seguir.

\subsection{Sistema de apoio à decisão $\mathrm{POC}^{\circledR}$ - preços, orçamentos e custos industriais}

O desenvolvimento do sistema POC ${ }^{\circledR}$, de acordo com Saraiva Jr., Costa e Ferreira (2013), é atribuído ao resultado de estudos realizados em mais de uma centena de pequenas e médias indústrias brasileiras de diferentes atividades econômicas, numa iniciativa de pesquisa integrada apoiada pela Fundação de Amparo à Pesquisa do Estado de São Paulo (FAPESP) através do programa de Projeto de Inovação em Pequenas Empresas (PIPE), e pela Fundação Carlos Alberto Vanzolini, instituição vinculada ao Departamento de Engenharia de Produção da Escola Politécnica da Universidade de São Paulo (PRO POLI USP).

O objetivo geral do sistema $\mathrm{POC}^{\circledR}$ é realizar, de forma acurada e rápida, várias simulações e análises quantitativas de apoio à tomada de decisão econômica empresarial, considerando o contexto industrial. As simulações e as análises decisórias são de natureza dinâmica, sendo 
aplicadas quando os gestores necessitam prever qual será o resultado de algo que se planeja realizar, ou de algo que irá fatalmente acontecer, ou, ainda, para alguma mudança que já aconteceu e cujo resultado ainda não foi observado (COSTA; FERREIRA; SARAIVA JR., 2010).

De acordo com Saraiva Jr., Costa e Ferreira (2013), o sistema POC ${ }^{\circledR}$ busca “automatizar" procedimentos e cálculos que são repetitivos e que, através de sua utilização adequada, possibilita economia de tempo do usuário (estudantes ou gestores de empresas) e acurácia nos cálculos e simulações de custos e de formação de preços de produtos. Costa, Ferreira e Saraiva Jr. (2010) pontuam que o sistema $\mathrm{POC}^{\circledR}$ serve de apoio à gestão econômica de operações, principalmente as de manufatura, no que tange aos seguintes items:

- Cálculo da margem de contribuição unitária, por tipo de produto e total da empresa;

- Quantificação de custos de produtos, subconjuntos e atividades;

- Orçamentação de pedidos;

- Formação de preço de venda de produtos;

- Simulação e análise econômica de substituição e alteração de recursos produtivos;

- Simulação e análise econômica de terceirizações de atividades, subconjuntos e produtos;

- Simulação e análise das relações custo-volume-lucro (CVL);

- Simulação e análise econômica do mix de produtos.

De acordo com Costa, Ferreira e Saraiva Jr. (2010), o sistema POC ${ }^{\circledR}$ pode auxiliar a gestão da produção ao contemplar, ainda, o planejamento de necessidade de materiais (do inglês Materials Requirements Planning - MRP I) de forma agregada; o planejamento de necessidades de recursos de manufatura (do inglês Manufacturing Resources Planning - MRP II - incluindo mão de obra e equipamentos) de forma agregada; o planejamento de capacidade para operações e máquinas (do inglês Capacity Resources Planning - CRP); a construção da curva ABC de custos de materiais e de faturamento produtos; e a construção do diagrama "de-para" utilizada em estudos sobre o layout fabril.

Em suma, o POC ${ }^{\circledR}$ pode ser compreendido como um sistema de modelagem econômicofinanceira que auxilia a gestão da produção. Essa afirmação fundamenta-se em dois aspectos principais. Primeiramente, a estrutura de análise para planejamento de preços e de combinação ótima de mix de produtos do sistema $\mathrm{POC}^{\circledR}$ é baseada na engenharia industrial. Ainda, os dados de entrada para os modelos de planejamento da produção que são, principalmente, as necessidades e as disponibilidades de recursos, os preços de venda e os custos dos recursos, das atividades e dos produtos, podem ser modelados e obtidos por meio do sistema POC ${ }^{\circledR}$ (SARAIVA JR.; COSTA; 
FERREIRA, 2013). Dentre pontos positivos do $\mathrm{POC}^{\circledR}$ como sistema de apoio à decisão empresarial, podem ser destacados (COSTA; FERREIRA; SARAIVA JR., 2010):

- Possui fácil operacionalização e entendimento;

- Possui baixo custo de implantação e de manutenção;

- É integrado a utilização de hardwares e sistemas operacionais compatíveis com a pequena, a média e a grande indústria;

- Utiliza métodos e técnicas simples e acuradas para apoiar as decisões sobre quantificação e análise de custos e formação de preços de produtos manufaturados;

- Integra as finanças da empresa com o marketing e a produção, através da construção das estruturas de produtos e subconjuntos, da documentação de processos de manufatura, e do levantamento de séries históricas das vendas de produtos na empresa;

- Possui base de dados relacionais que podem ser integrada com outras funcionalidades e sistemas transacionais (ex: sistema de folha de pagamento, comercial, etc.) e com sistemas ERP (Enterprise Resource Planning);

- Apresenta documentação de engenharia industrial estruturada e com facilidade de simulação de cenários em termos de estrutura de produto e processo de produção;

- Possui potencial de generalização para diversos tipos de atividades econômicas e sistemas de produção (por processo e por ordem de produção).

A Figura 1 traz uma representação geral de como o sistema $\mathrm{POC}^{\circledR}$ estrutura a integração de informações das funções básicas da empresa.

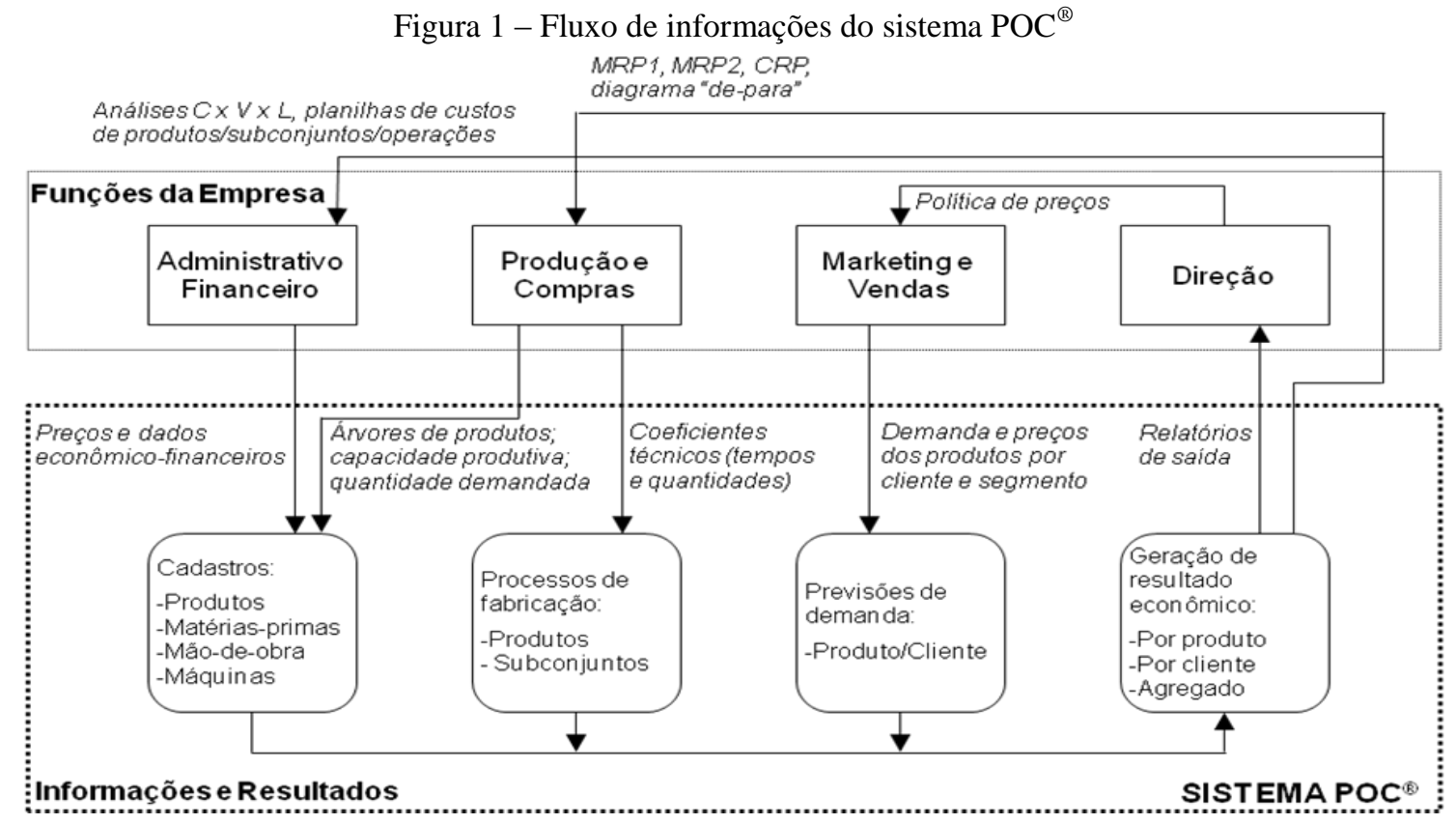

Fonte: Costa, Ferreira e Saraiva Jr. (2010) 
Vale destacar os itens que compõem a estrutura de gastos considerada pelo sistema POC® para realizar a modelagem econômica de operações industriais (COSTA; FERREIRA; SARAIVA JR., 2010):

- Custos diretos: custos de materiais diretos, de mão de obra direta e de utilidades (ex: energia elétrica) formados a partir do levantamento de coeficientes técnicos de tempo e de consumo de materiais (inclusive os itens de "terceiros");

- Despesas variáveis de venda: itens de impostos, taxas, comissões e despesas comerciais diversas que variam com o volume de vendas;

- Custos e despesas fixos: mão de obra fixa (ex: gerentes, supervisores, técnicos de segurança, engenheiros, etc.), aluguéis, materiais de escritório, despesas administrativas, pró-labore, entre outros.

O sistema $\mathrm{POC}^{\circledR}$ segue uma metodologia baseada no cálculo da margem de contribuição e no método de custeio direto/variável. No entendimento de Brunstein (2005), Padoveze (2006), Saraiva Jr., Tabosa e Costa (2009) e Martins (2010), a margem de contribuição permite identificar o valor que cada unidade de produto, tipo de produto, família de produto, pedido específico, cliente, segmento de mercado, ou unidade de negócio proporciona à empresa de sobra entre a sua receita e o gasto que de fato tenha provocado. Costa, Ferreira e Saraiva Jr. (2010) pontuam que o sistema POC $^{\circledR}$ busca quantificar a margem de contribuição unitária por produto, total por tipo de produto e total da empresa, dado um plano de produção, ou seja, um mix (tipos e quantidades) de produtos. Assim, modela-se o conjunto de margens individuais que, somadas, devem ser comparadas com os custos e despesas fixos para se calcular o lucro operacional da empresa em determinado período (ex: mês). Convém observar que, embora seja utilizado para fins de tomada de decisões gerenciais, o método de custeio direto/variável não se adequa à legislação e às normas contábeis e fiscais brasileiras (BRUNI e FAMÁ, 2009).

\section{Aplicação do sistema $\mathrm{POC}^{\circledR}$ na indústria cerâmica}

Nesta seção, inicialmente são apresentados e discutidos aspectos relacionados com o processo produtivo de produtos da cerâmica vermelha. Em seguida, a indústria estudada é caracterizada. Por fim, são explicitados, de forma detalhada, os procedimentos realizados para a operacionalização do sistema POC, além dos resultados obtidos com a modelagem econômica da empresa estudada.

\subsection{O processo produtivo da cerâmica vermelha}

De acordo com a Associação Brasileira de Cerâmica (ABC, 2014), geralmente são usados dois ou mais tipos de argila como matéria-prima para a composição dos materiais cerâmicos, além 
de aditivos e água. A Figura 2 apresenta o processo geral de fabricação produtos de cerâmica vermelha.

Figura 2 - Processo de fabricação de cerâmica vermelha

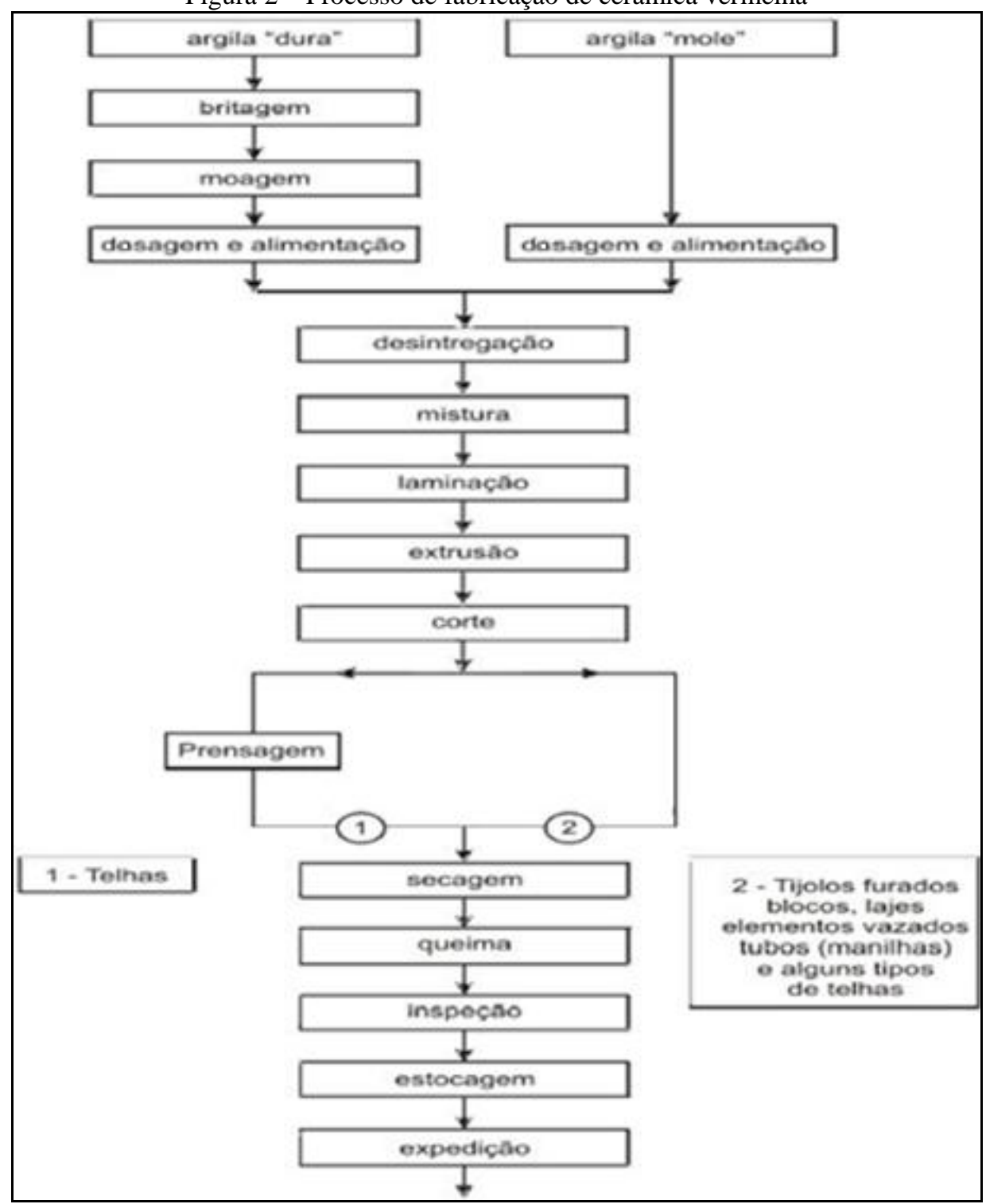

Fonte: ABC (2014)

Convém observar que uma das etapas mais importantes do processo produtivo é a dosagem das matérias-primas e dos aditivos, que deve seguir rigorosamente as formulações de massas previamente estabelecidas. No caso da argila dura, quando esta está muito seca e dura, passa pelo processo da britagem para ser quebrada em partes menores. Na sequência do processo, a argila dura passa pelo pelo processo de moagem para, novamente, quebrar os grânulos maiores em menores para homogeneizar a granulometria das partículas sólidas. Por sua vez, a argila mole não passa por os dois últimos processos supracitados.

$\mathrm{Na}$ sequência do processo produtivo, as matérias-primas, já na forma de "massa", são dosadas e alimentadas por um caixão-alimentador que serve para controlar a quantidade a ser 
processada pelos equipamentos subsequentes. Posteriormente, a massa vai para o processo de mistura que consiste de um equipamento com facas circulares que cortam a argila e serve para controlar a umidade e homogeinizar a massa. A etapa seguinte consiste no processo de laminação que envolve, normalmente, a utilização de uma prensa que compacta a argila, tornando-a menos porosa e com maior densidade. Em seguinda, a massa de argila e os complementos passam pelo processo de extrusão. Ao ser processado pelo equipamento de extrusão, o corpo cerâmico apresenta-se unido e em um formato inicial próximo ao desejado aos produtos da linha de produção.

A produção segue com o processo de corte em que se dá o formato da peças cerâmicas de diferentes tamanhos e formas. No caso da fabricação das telhas, normalmente são utilizadas prensas para se ober o formato final dos produtos. Por sua vez, a fabricação de tijolos furados, blocos, lajes, elementos vazados, e alguns tipos de telhas não necessitam da prensagem após o processo de corte. Desta forma, seguem diretamente para o processo seguinte: a secagem. Este processo objetiva remover a água do corpo cerâmico formado.

Após a secagem, os corpos cerâmicos são transportadas em lotes para a próxima etapa do processo produtivo: a queima. O processo de queima é constituído de fornos que servem para calcinar os corpos cerâmicos moldados em altas temperaturas. No processo de queima, ocorrem transformações físico-químicas que alteram os corpos cerâmicos em termos de propriedades mecânicas, coloração e dimensões. Convém observar que a temperatura de queima é de 750 a $900^{\circ} \mathrm{C}$ para tijolos, e de 900 a $950^{\circ} \mathrm{C}$ para telhas.

Após o processo de queima, os produtos cerâmicos passam por uma inspeção de qualidade para identificar itens defeituosos que apresentam sinais de quebra, trincas ou coloração inadequada. Após a realizaçao do processo de inspeção, os produtos satisfatórios são armazenados para, em seguida, serem expedidos, normalmente, pelo modal logístico rodoviário através do uso de caminhões.

\subsection{Caracterização da empresa estudada}

O estudo foi realizado em uma empresa do setor de cerâmica do estado do Rio Grande do Norte. Atuante no mercado a mais de 20 anos, a empresa abastece o mercado local e de estados vizinhos, sendo os principais: Bahia, Paraíba, Pernambuco e Ceará. A empresa busca inovar em termos de desenvolvimento de novos produtos, possuindo um portfólio diversificado com 12 produtos.

Os produtos estão divididos em dois grupos: produtos brancos e produtos vermelhos. A principal diferença entre eles refere-se ao tipo de argila. A linha de produtos brancos é composta pelos seguintes produtos cerâmicos finais: Telha Plan Branca, Telha Colonial Prensada Branca, Telha Cumeeira Branca, Telhinha, Telhão Branco, Casquilho Branco, Tijolo Aparente Branco e Tijolo Comum Branco. Já a linha de produtos vermelhos é composta por Telha Colonial Vermelha, 
Tijolo 09 x 19 x 24, Lajota Grande e Lajota Pequena. A Figura 3 traz a ilustração dos produtos da empresa analisada, com exceção da lajota pequena que é semelhante à Lajota Grande em tamanho menor e da Telhinha que é semelhante ao Telhão, em tamanho menor.

Figura 3 - Portfólio de produtos da empresa

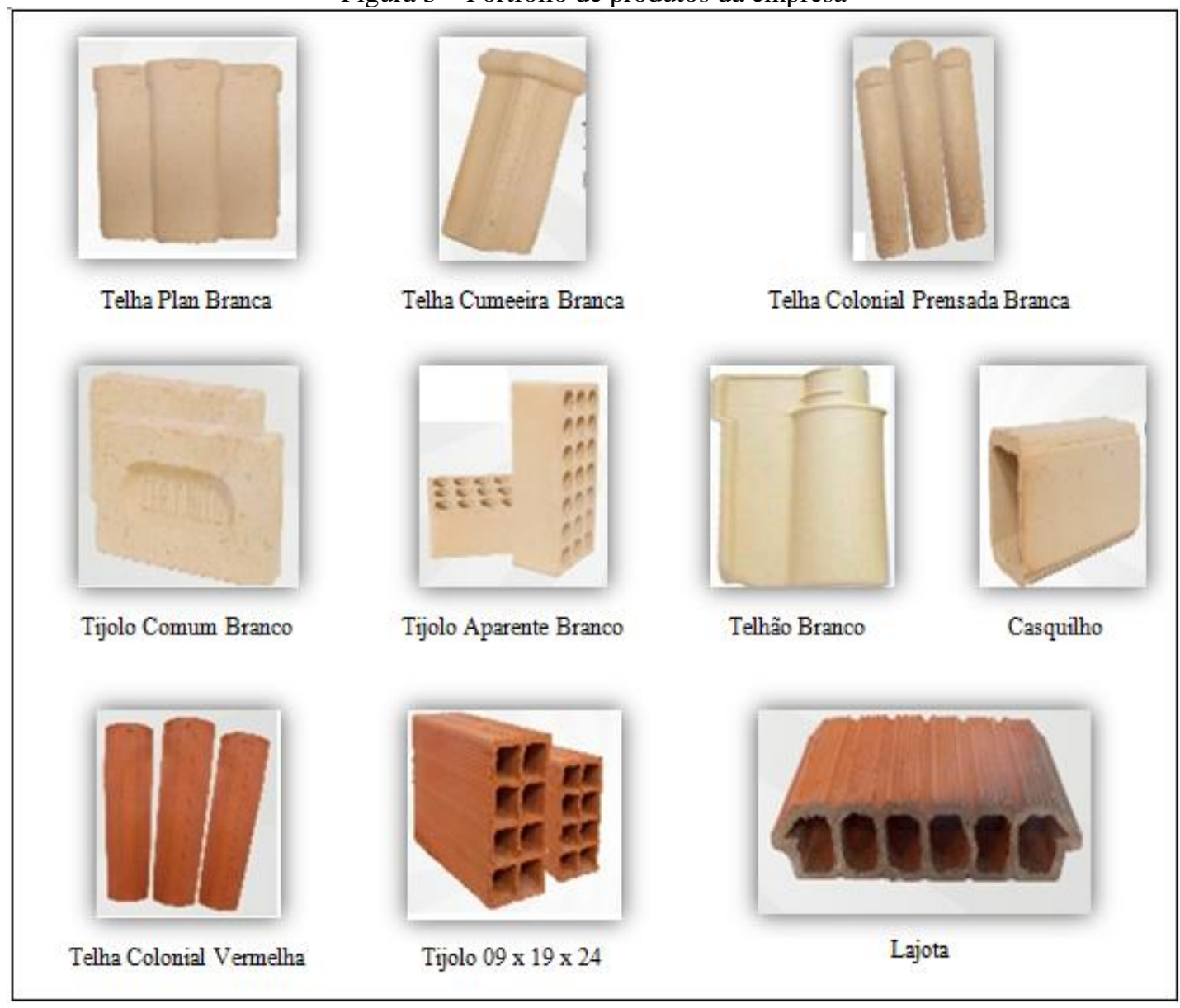

Fonte: Autoria própria (2014)

Convém ressaltar que a modelagem econômica da indústria ceramista através do sistema POC $^{\circledR}$ considerou os 12 produtos supracitados.

\section{3. $\quad$ Entrada de dados no sistema POC $^{\circledR}$}

Para operacionalizar o sistem POC $^{\circledR}$, a entrada de dados foi iniciada através da funcionalidade "cadastro primário". Foram cadastrados os custos e as despesas fixas da organização, as unidades que serão utilizadas (ex: $\mathrm{kg}, \mathrm{m}^{2}$, etc), os impostos incidentes (ex: IPI, ICMS, etc.), as condições de pagamento e a moeda utilizada. Quanto aos impostos, observou-se que a empresa é optante pelo Simples Nacional. Assim, de acordo com a receita brita anual da organização, foi possível, através da tabela do Simples Nacional, obter a alíquota incidente sobre os preços de venda de $8,78 \%$. As Figuras 4 e 5 apresentam, respectivamente, o cadastro dos custo fixos (também indiretos em relação aos produtos) mensais e das despesas fixas mensais. 
Figura 1 - Cadastro de custos fixos do período no sistema POC $^{\circledR}$

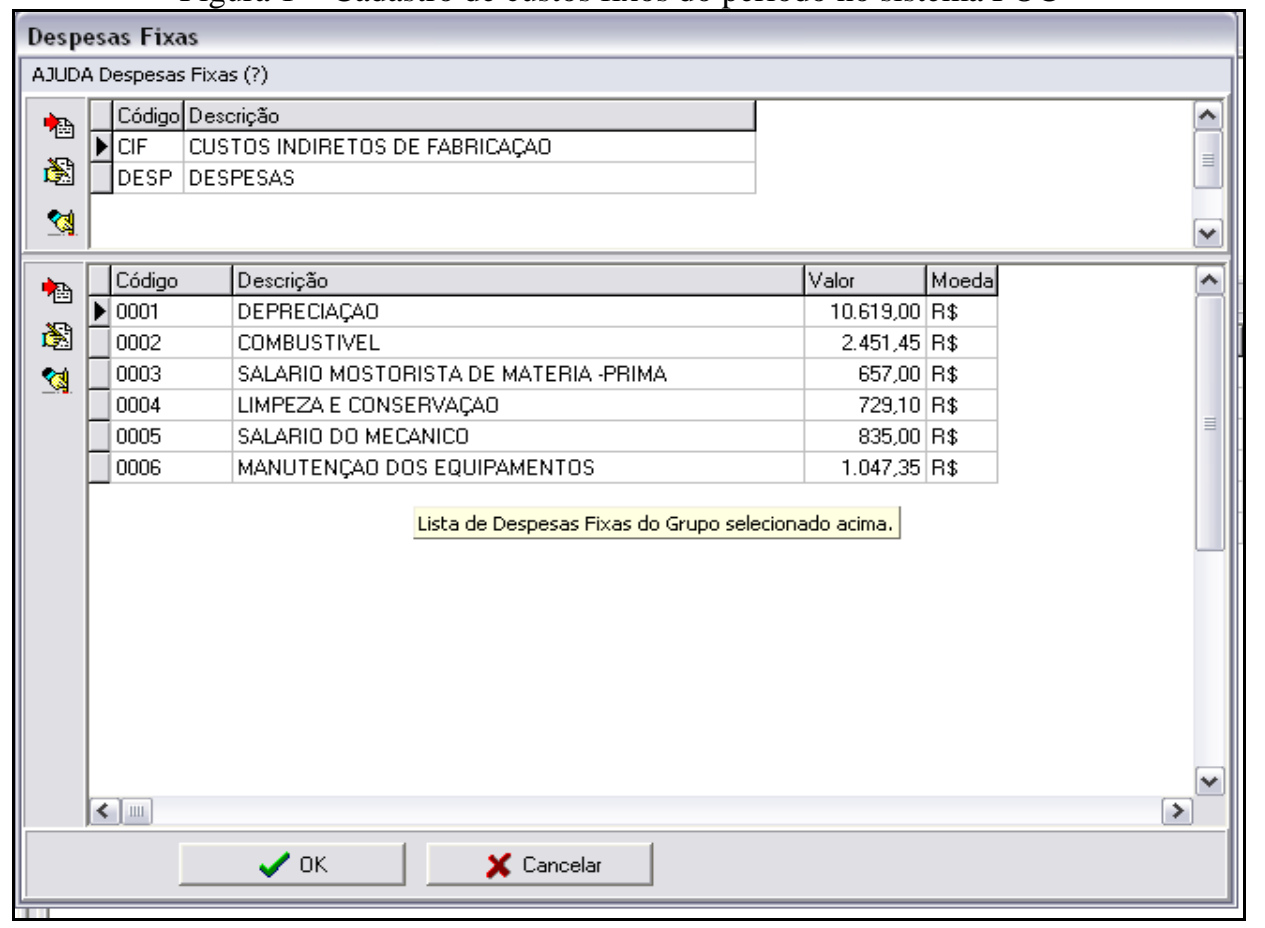

Fonte: Autoria própria (2014)

Figura 5 - Cadastro de despesas fixas do período no sistema $\mathrm{POC}^{\circledR}$

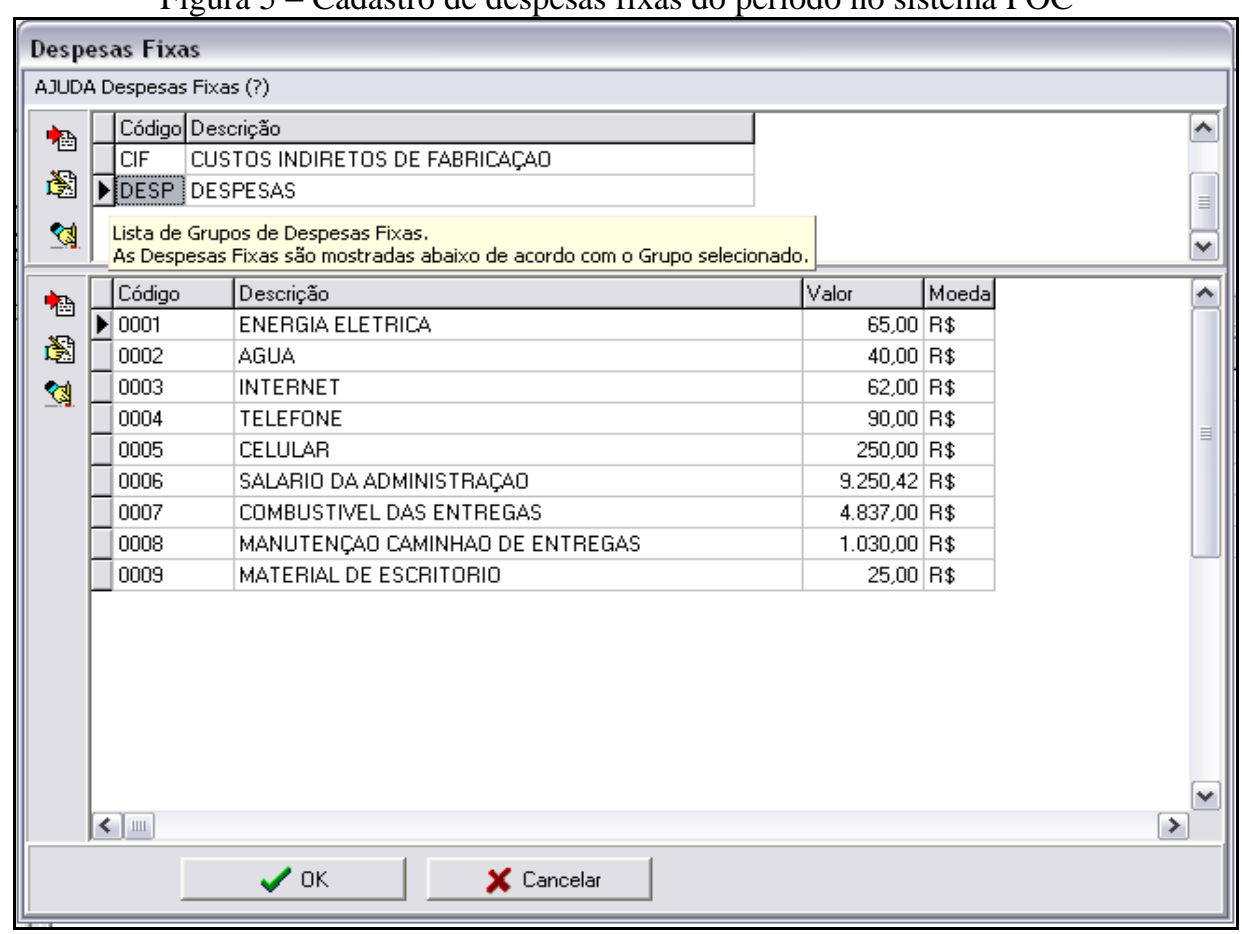

Fonte: Autoria própria (2014)

\subsection{Cadastro principal}

$\mathrm{Na}$ funcionalidade "cadastro principal" do sistema $\mathrm{POC}^{\circledR}$, foram cadastrados tantos os produtos finais, como também os materiais diretos, a mão de obra direta, as operações e as máquinas inerentes ao processo produtivo. Após entendimento do potfólio da indústria estudada, foi iniciada a realização do cadastro dos produtos no sistema POC $^{\circledR}$. Para tal, foram especificadas informações relativas à quantidade mensal média vendida, à unidade de venda ("mil" = milheiro), 
ao preço de venda líquido de impostos sobre vendas ("valor"), à moeda utilizada ("R\$") e aos impostos que incidem sobre as vendas (Simples Nacional). As Figuras 6 e 7, respectivamente, apresentam o cadastro dos produtos da linha de argila branca e os da linha de argila vermelha.

Figura 6 - Cadastro do produtos finais da linha de argila branca no sistema POC $^{\circledR}$

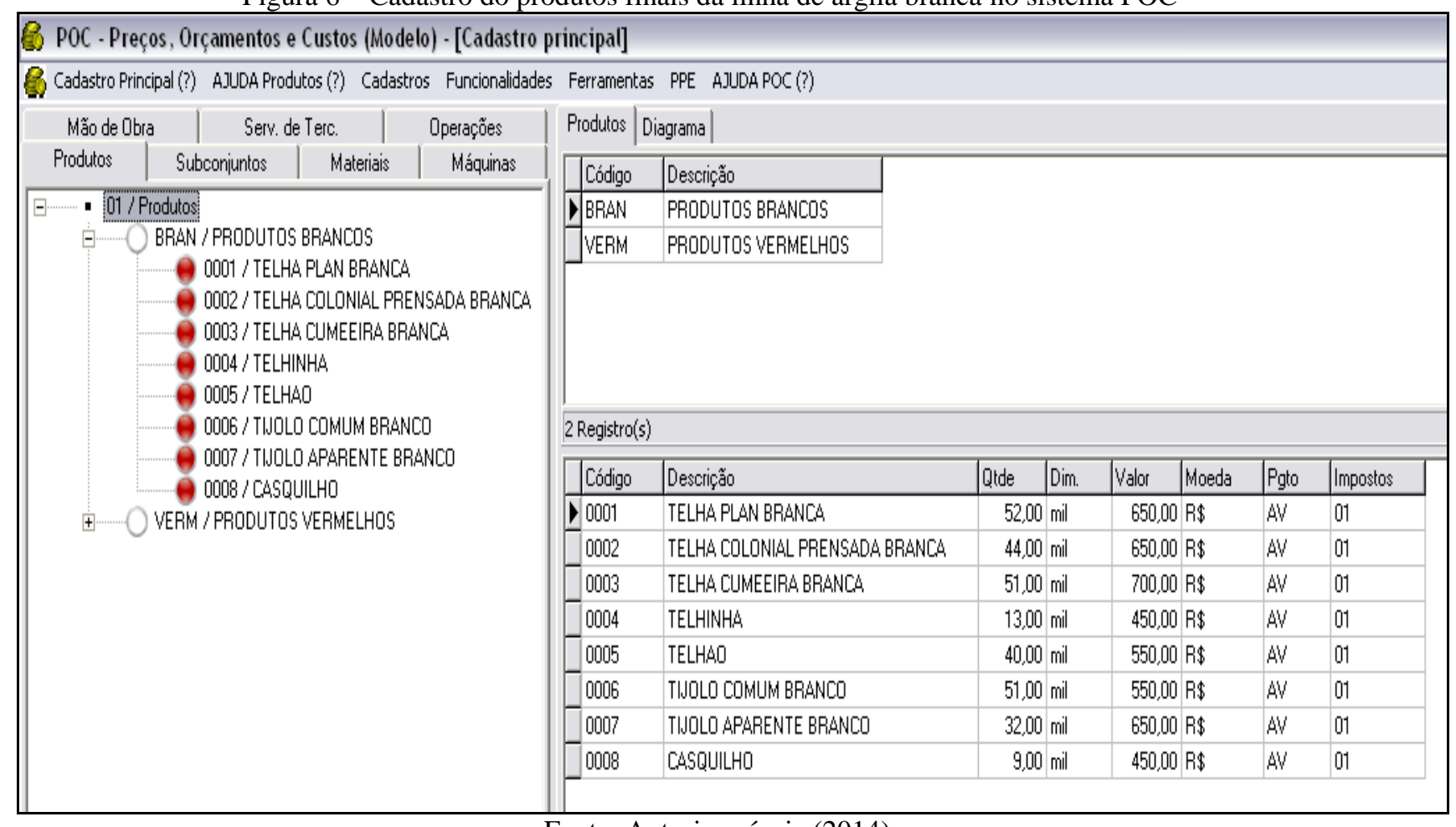

Fonte: Autoria própria (2014)

Figura 7 - Cadastro do produtos finais da linha de argila vermelha no sistema POC $^{\circledR}$

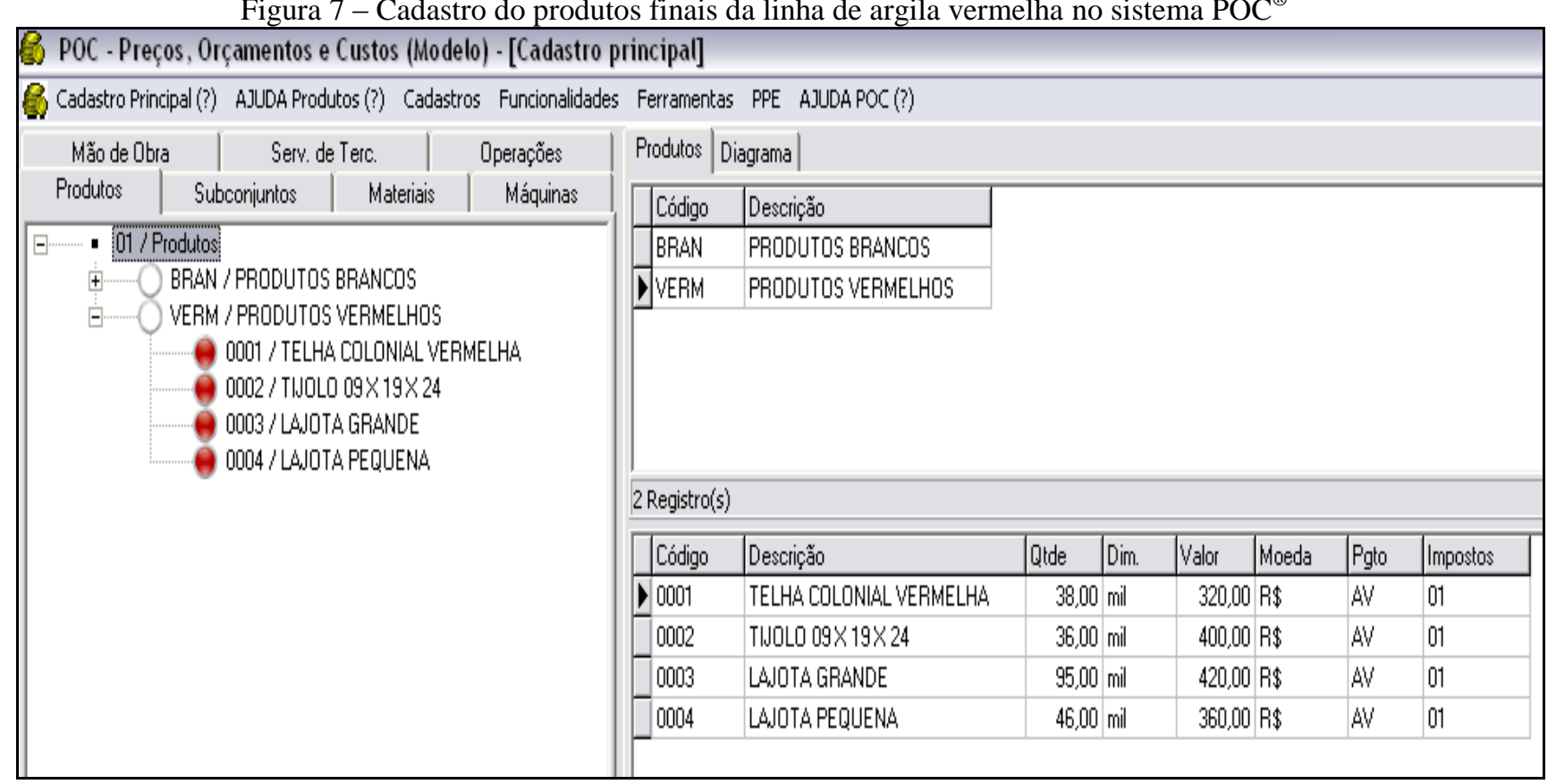

Fonte: Autoria própria (2014)

Em termos de materiais e utilidades utilizados diretamente no processo produtivo, foram identificados: argila, água, lenha, energia e óleo lubrificante (utilizado em alguns produtos apenas). Na produção, a empresa utiliza dois tipos de argila: um para os produtos brancos e outro para os 
produtos vermelhos. A primeira argila é de um tipo especial e seu custo de aquisição é superior ao da segunda. No estudo, a quantidade de argila foi determinada a partir da diferença de peso do produto antes da secagem e do peso do produto final. Com isso, foi possível calcular a porcentagem de água e o peso seco, ou seja, o peso da argila sem a adição da água, como mostra a Figura 8.

Figura 8 - Peso dos produtos e porcentagem de água utilizada

\begin{tabular}{|l|c|c|c|}
\hline \multicolumn{1}{|c|}{ PRODUTO } & $\begin{array}{c}\text { Peso Seco } \\
(\mathrm{Kg})\end{array}$ & $\begin{array}{c}\text { Peso Molhado } \\
(\mathrm{Kg})\end{array}$ & $\begin{array}{c}\text { Porcentagem } \\
\text { de Água }\end{array}$ \\
\hline Tijolo Aparente Branco & 2,00 & 2,50 & $25,00 \%$ \\
\hline Telha Cumeeira Branca & 2,50 & 2,50 & - \\
\hline Telha Colonial Prensada Branca & 1,90 & 2,20 & $15,79 \%$ \\
\hline Telha Plan Branca & 1,95 & 2,20 & $12,82 \%$ \\
\hline Telhão & 2,35 & 2,90 & $23,40 \%$ \\
\hline Tijolo Comum Branco & 2,00 & 2,52 & $26,00 \%$ \\
\hline Casquilho & 0,80 & 1,00 & $25,00 \%$ \\
\hline Telhinha & 1,25 & 1,50 & $20,00 \%$ \\
\hline Lajota Pequena & 3,10 & 3,50 & $12,90 \%$ \\
\hline Tijolo 09x 10 x 24 & 3,30 & 3,75 & $13,64 \%$ \\
\hline Telha Colonial Vermelha & 1,45 & 1,60 & $10,34 \%$ \\
\hline Lajota Grande & 3,45 & 3,82 & $10,72 \%$ \\
\hline
\end{tabular}

Fonte: Autoria própria (2014)

O custo relativo ao consumo de água foi calculado de forma indireta, levando-se em consideração apenas a água utilizada na produção. Ressalta-se que a água utilizada no processo produtivo é retirada de um rio cujo leito passa por dentro do terreno da fábrica. Assim, o custo com água provém do bombeamento desta e não da sua aquisição propriamente dita. Para se calcular o custo com água, foi necessário conhecer a potência e a capacidade de vazão por hora do equipamento de bombeamento, determinando o volume de água extraída e a quantidade de horas em funcionamento da bomba. Esse custo foi calculado tomando como base a quantidade de produtos produzidos no turno de produção, conseguindo-se, assim, determinar a quantidade de água para cada produto produzido e, portanto, para um milheiro de produtos.

Para o cálculo da lenha consumida, foi utilizado um raciocínio similar. Definiu-se a quantidade de lenha necessária para a queima de um milheiro de cada produto e, posteriormente, para a unidade de cada produto. Conhecendo o custo de aquisição de $1 \mathrm{~m}^{3}$ de lenha, pôde-se definir o custo com lenha para uma unidade de produto e, consequentemente, para um milheiro. Para o cálculo da energia elétrica, foi necessário conhecer a potência das máquinas envolvidas no processo produtivo e o custo do Kwh. Por último, o consumo de óleo lubrificcante foi calculado tanto para o milheiro de cada produto, como também para a unidade produzida, considerando que alguns produtos tais como telha plan branca, telha colonial prensada branca, telha cumeeira branca telhinha e telhão eram demandantes de óleo lubrificantes para não grudarem nos moldes das prensas mecânicas utilizadas no processo de produção. 
Após entendimento dos materiais utilizados, foi iniciada a realização do cadastro dos materiais diretos no sistema $\mathrm{POC}^{\circledR}$. Para tal, foram especificados todos os componentes materiais utilizados na produção dos produtos finais, com informações relativas à dimensão, ao peso e ao custo de aquisição ("valor") já considerando os impostos que incidem sobre a compra, conforme apresentado na Figura 9.

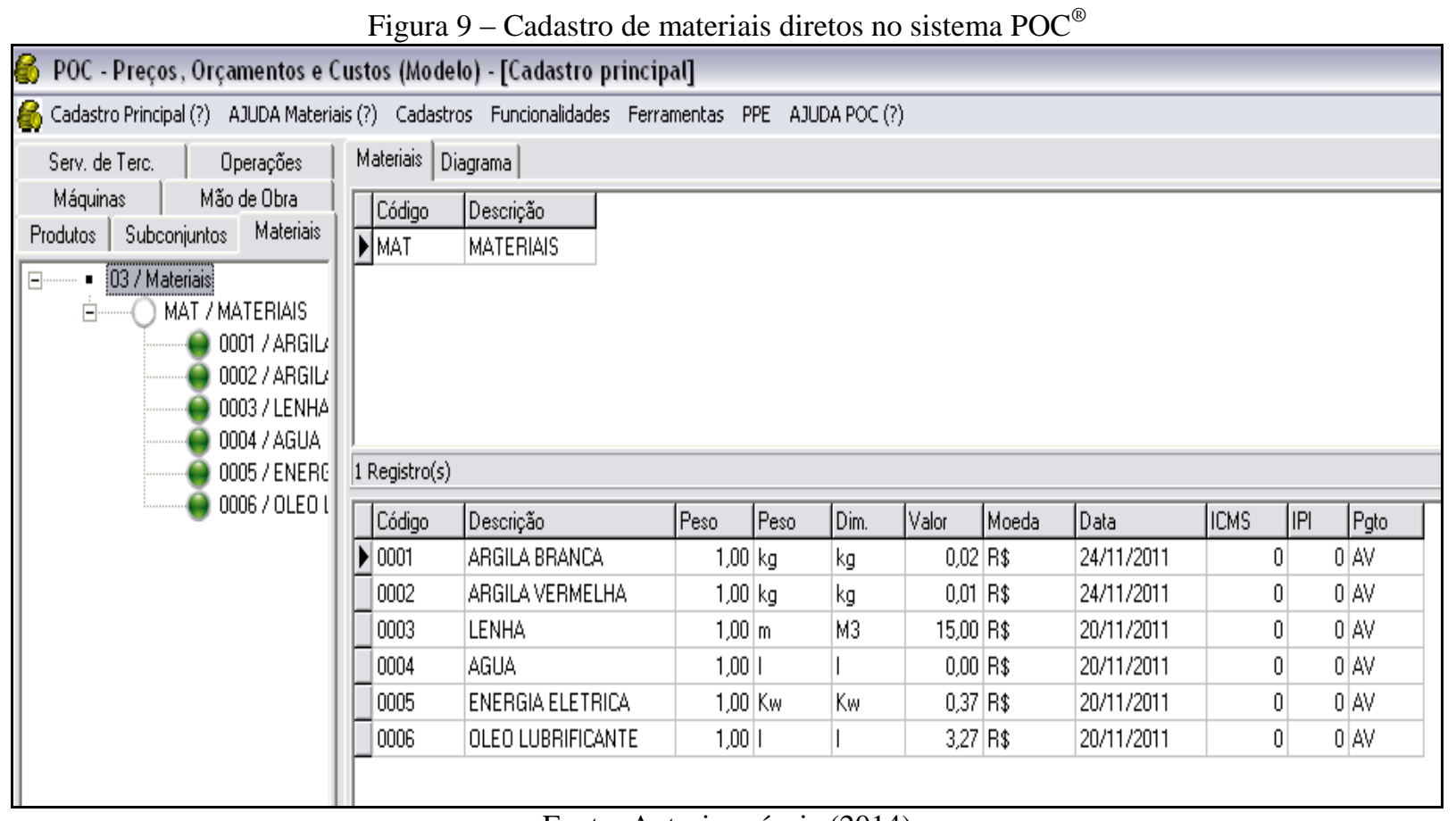

Fonte: Autoria própria (2014)

Convém observar que os materiais são basicamente os mesmos para todos os produtos finais, sendo a principal diferença o tipo de argila empregado no processo produtivo. Esse insumo varia dos produtos brancos para os produtos vermelhos. Para os produtos brancos, a argila é de um tipo especial e com maior custo de aquisição, o que é refletido diretamente nos preços dos produtos finais. Já os produtos cerâmicos vermelhos são fabricados com argila comum geralmente encontrada em cerâmicas da região. $\mathrm{O}$ custo de aquisição da argila foi medido em toneladas, com isso foi possível chegar ao preço de um quilograma de cada tipo de argila.

$\mathrm{Na}$ sequência do estudo, foi realizado o cadastro da mão de obra direta sistema $\mathrm{POC}^{\circledR}$. Nesse cadastro, foi considerado apenas o trabalho do pessoal que está diretamente ligado à produção propriamente dita, correspondendo a um total de 24 operadores. Após identificadas a remuneração e a carga horária de trabalho mensais dos operários, foi mensurado o custo hora/homem da mão de obra direta. Ressalta-se que foram considerados encargos sociais e benefícios e que a carga de trabalhado dos operários observada foi de 192 horas por mês, em média. Nos casos dos operários do tipo Arrumador, Barreirista, Desenfornador, Enfornador, Lenheiro, Pegador, Tareiro, Transportador/Carregador e Queimador, o custo médio calculado foi de R\$ 2,83 por hora. Para o tipo Operador de Máquinas e Aguardor, o custo médio foi, respectivamente, de R\$3,15 e R\$3,77 
por hora. Por fim, foi estimado o custo de $\mathrm{R} \$ 4,77$ por hora de trabalho dos operadores do tipo Carregador de Carrinho e Operário de Produção-Lavra. A Figura 10 mostra o cadastro de mão de obra direta no sistema POC ${ }^{\circledR}$.

Figura 10 - Cadastro de mão de obra direta no sistema $\mathrm{POC}^{\circledR}$

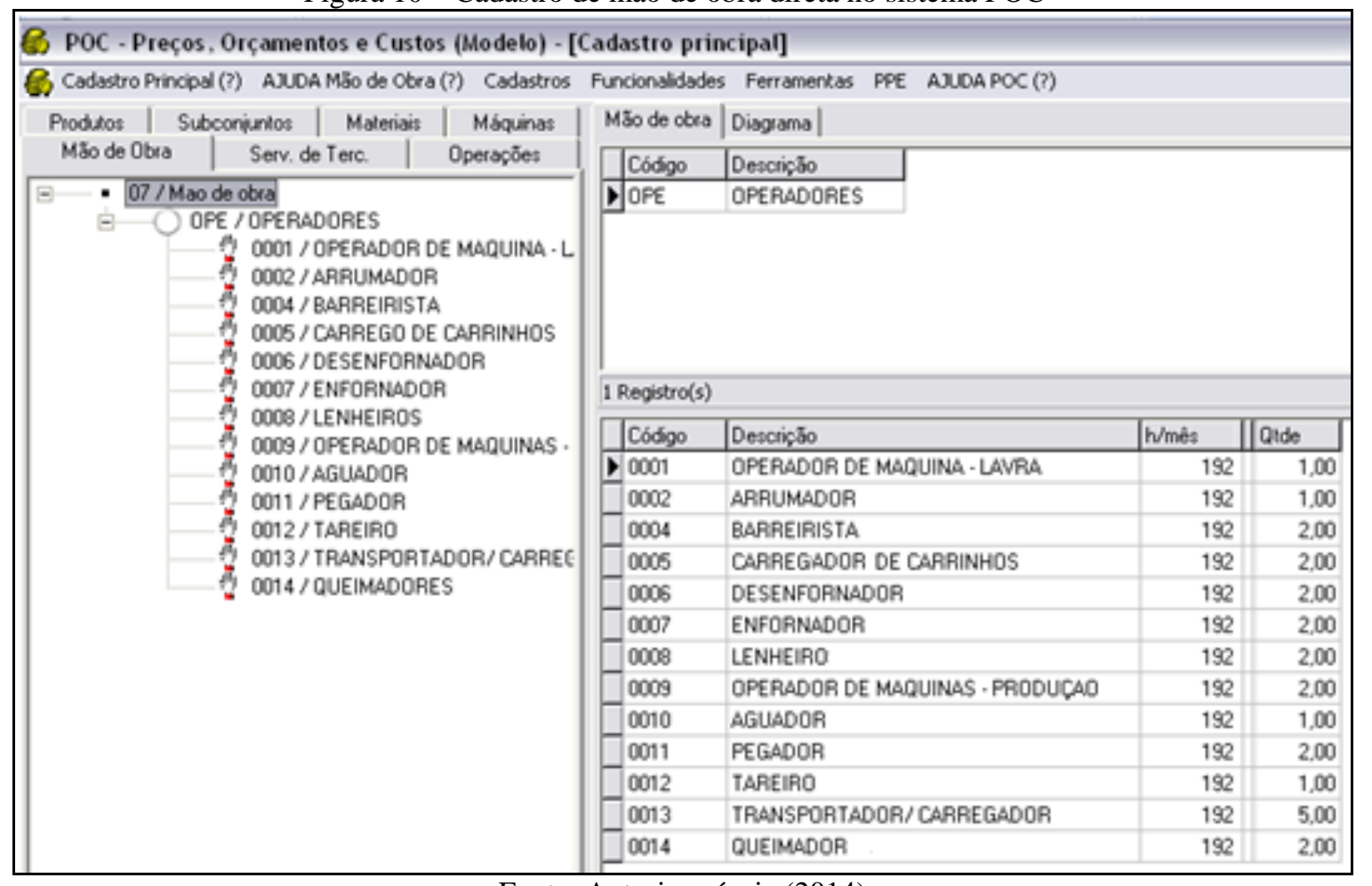

Fonte: Autoria própria (2014)

O cadastro primário do sistema $P O C{ }^{\circledR}$ prosseguiu com a informação das operações existentes ao longo do processo produtivo, considerando agrupamentos por tipo de produto fabricado. Convém ressaltar que os processos produtivos são muito semelhantes e basicamente seguem o mesmo procedimento na forma de linha de produção. A Figura 11 apresenta as operações para os produtos finais do tipo telha plan branca, telha cumeeira branca, telha colonial prensada branca, telhinha e telhão. Já a Figura 12 apresenta as operações dos produtos do tipo casquilho branco, tijolo aparente branco, telha colonial vermelha, tijolo 09 x19 x 24, lajota grande e lajota pequena. Ressalta-se que o único produto que difere dos demais em termos de necessidade de operações produtivas é o tijolo comum branco, como mostra a Figura 13. 
Figura 11 -2 Cadastro, no sistema $\mathrm{POC}^{\circledR}$, das operações de fabricação dos produtos telha plan branca, telha colonial prensada branca, telhinha, telhão e telha de cumeeira branca

\begin{tabular}{|c|c|c|c|}
\hline \multicolumn{4}{|c|}{9 POC - Preços, Orçamentos e Custos (Modelo) - [Cadastro principal] } \\
\hline \multirow{2}{*}{\multicolumn{4}{|c|}{$\begin{array}{l}\text { 9. Cadastro Principal (?) AJUDA Operaçōes (?) Cadastros Funcionalidades Ferramentas PPE } \\
\text { Produtos | Subconiuntos | Materiais | Máquinas | Operações |Diagrama | }\end{array}$}} \\
\hline & & & \\
\hline \multicolumn{2}{|r|}{ Serv. de Terc. } & \multicolumn{2}{|c|}{ 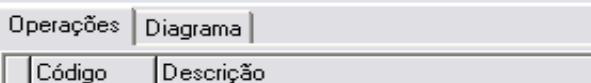 } \\
\hline \multirow{28}{*}{\multicolumn{2}{|c|}{ 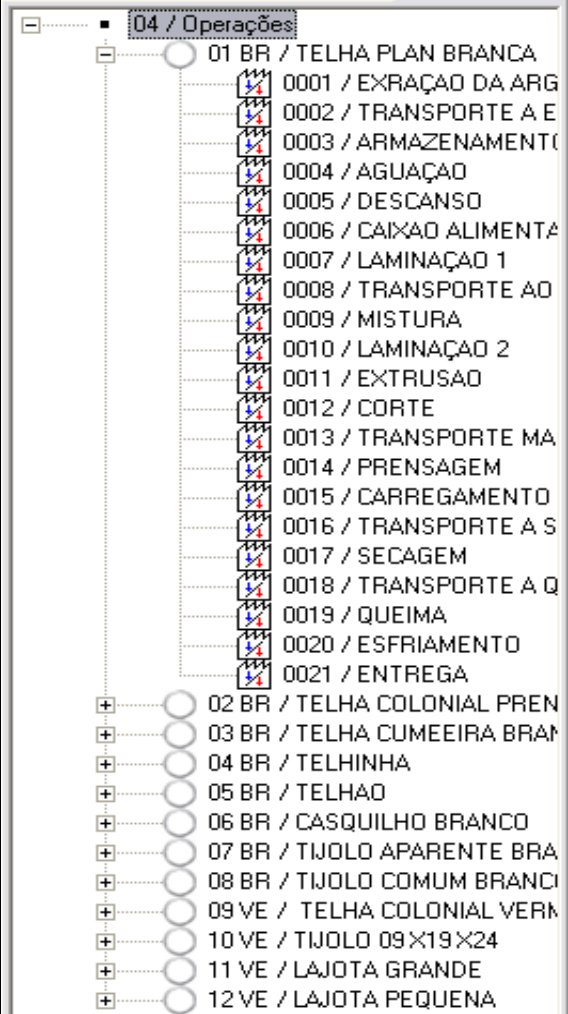 }} & $01 \mathrm{BR}$ & TELHA PLAN BRANCAA \\
\hline & & $02 \mathrm{BR}$ & TELHA COLONIAL PRENSADA BRANCA \\
\hline & & $03 \mathrm{BR}$ & TELHA CUMEEIRA BRANCA \\
\hline & & $04 \mathrm{BR}$ & TELHINHA \\
\hline & & $05 \mathrm{BR}$ & TELHAOO \\
\hline & & Do6 B & CASQUILHO BRANCO \\
\hline & & \multicolumn{2}{|c|}{12 Registro(s) } \\
\hline & & Código & Descrição \\
\hline & & 0001 & EXRACAO DA ARGILA \\
\hline & & - 0002 & TRANSPORTE A EMPRESA \\
\hline & & 0003 & ARMAZENAMENTO \\
\hline & & 0004 & AGUAC,AO \\
\hline & & 0005 & DESCANSO \\
\hline & & 0006 & CAIXAO ALIMENTADOR \\
\hline & & 0007 & LAMINACCAOO 1 \\
\hline & & 0008 & TRANSPORTE AO MISTURADOR \\
\hline & & 0009 & MISTURA \\
\hline & & 0010 & LAMINAC,AO 2 \\
\hline & & 0011 & EXTRUSAO \\
\hline & & 0012 & CORTE \\
\hline & & 0013 & TRANSPORTE MANUAL A PRENSA \\
\hline & & \begin{tabular}{|l}
0014 \\
0015
\end{tabular} & $\begin{array}{l}\text { PRENSAGEM } \\
\text { CARREGAMENTO DE CA.RRINHOS }\end{array}$ \\
\hline & & - 0016 & $\begin{array}{l}\text { CARREGAMMENTU DE LA.RFINHOS } \\
\text { TRANSPORTE A SECAGEM }\end{array}$ \\
\hline & & 0017 & SECAGEM \\
\hline & & 0018 & TRANSPORTE A QUEIMA \\
\hline & & 0019 & QUEIMA \\
\hline & & 0020 & ESFRIAMENTO \\
\hline & & 0021 & ENTREGA \\
\hline
\end{tabular}

Fonte: Autoria própria (2014)

Figura 12 -3 Cadastro, no sistema POC $^{\circledR}$, das operações de fabricação dos produtos casquilho branco, tijolo aparente branco, telha colonial vermelha, tijolo $09 \times 19$ × 24, lajota grande e lajota pequena.

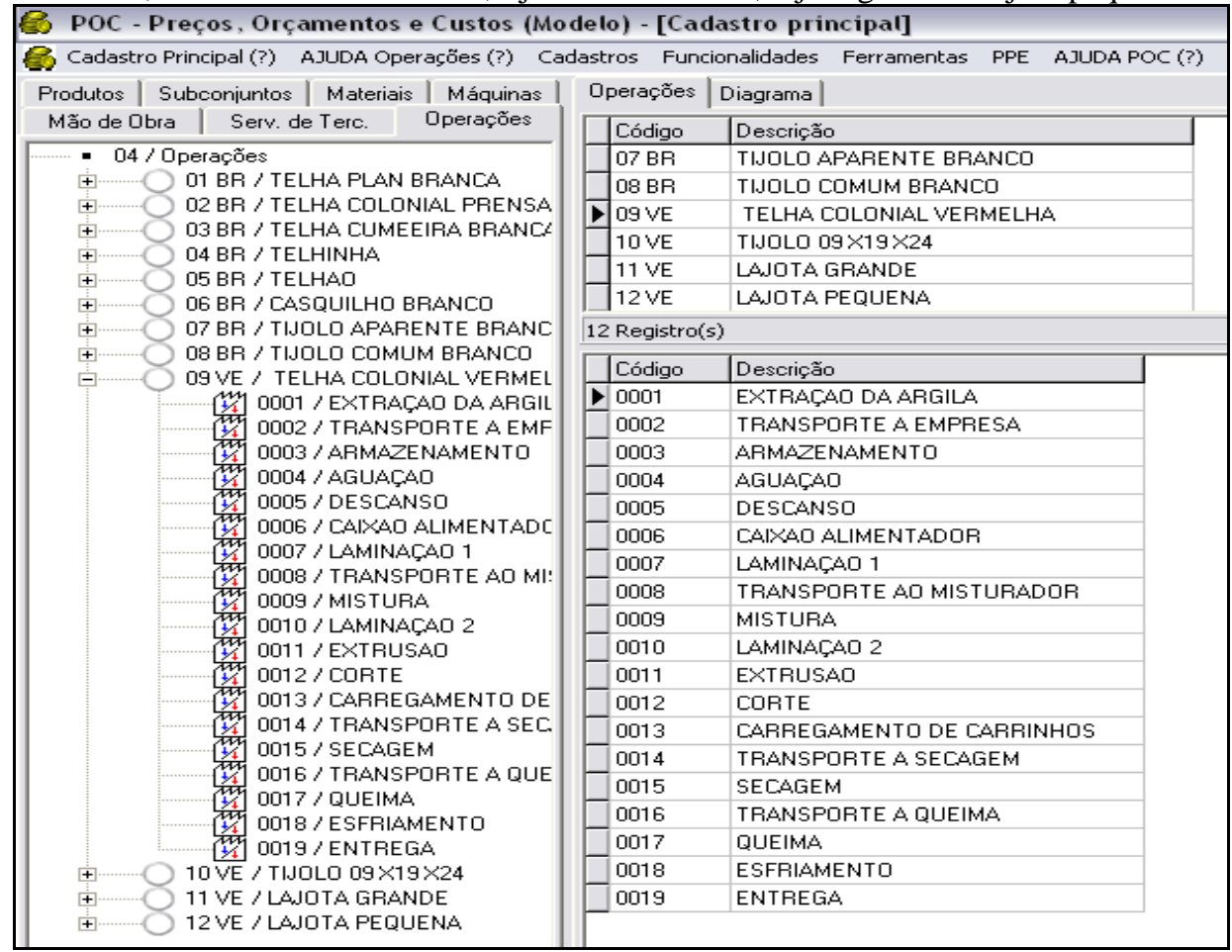

Fonte: Autoria própria (2014) 
Figura 13 -4 Cadastro, no sistema $\mathrm{POC}^{\circledR}$, das operações de fabricação do produto tijolo comum branco

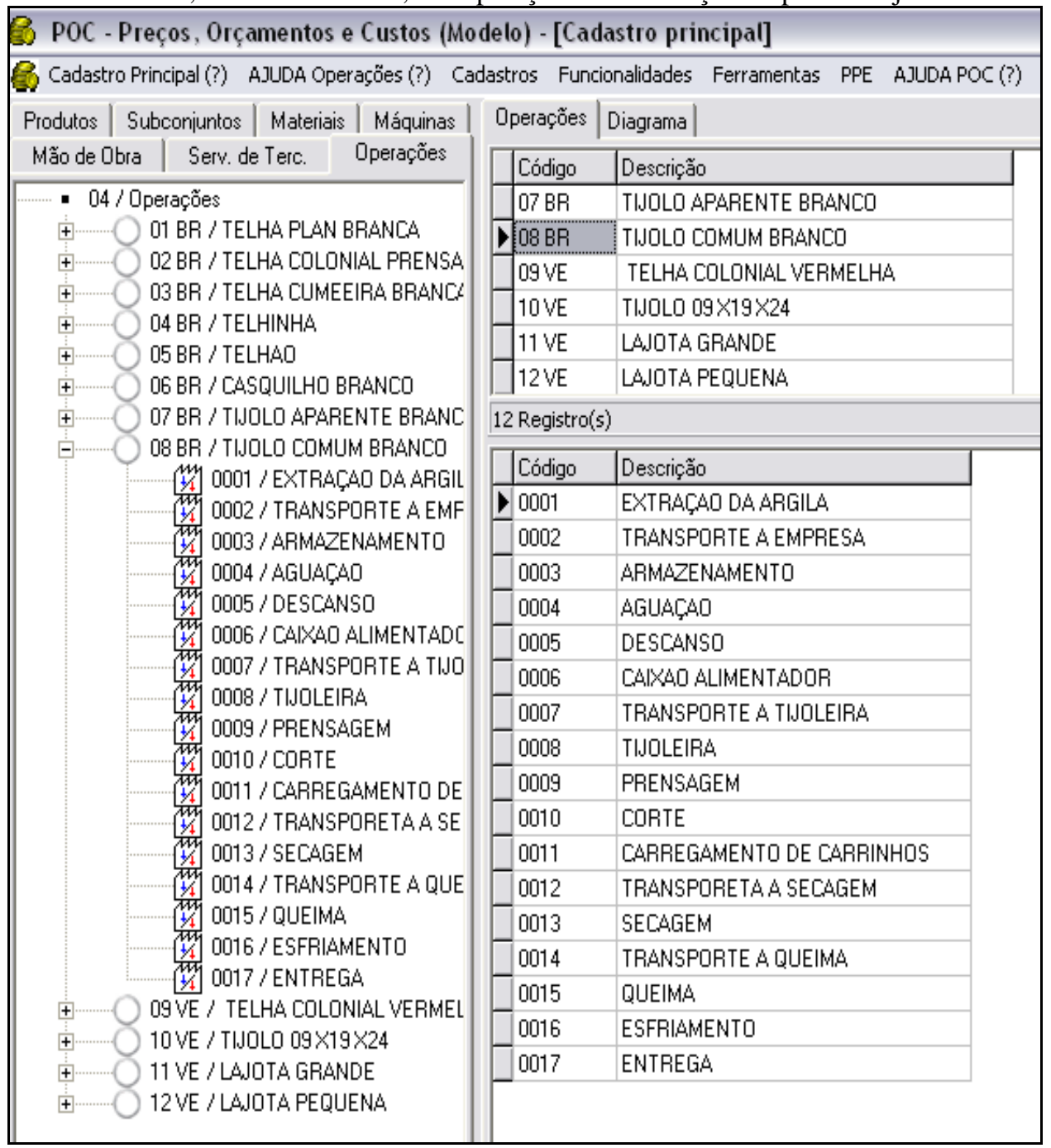

Fonte: Autoria própria (2014)

O cadastro primário foi finalizado com o registro das informações relativas às máquinas utilizadas no processo produtivo, incluindo: tipo de máquina, quantidade de máquinas, valor das máquinas, vida útil, quantidade de horas que é utilizada por dia e a potência em watts. Essas informaçoes serviram de base para o cálculo do custo de energia elétrica decorrentes da utilização das máquinas. $\mathrm{O}$ cadastro das máquinas contabilizou quatorze máquinas diferentes, como mostra a Figura 14.

Figura 14 - Cadastro de máquinas no sistema $\mathrm{POC}^{\circledR}$

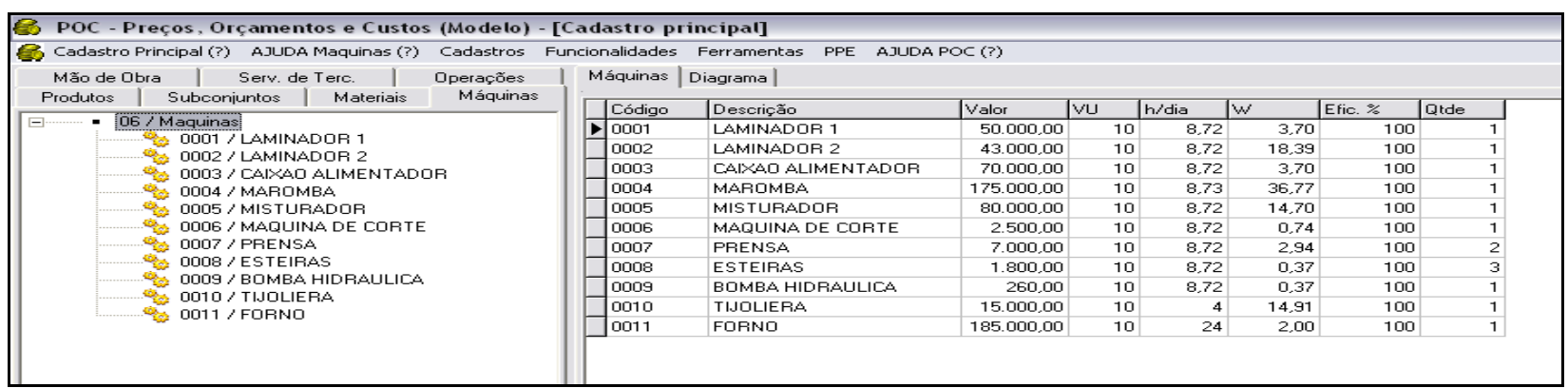

Fonte: Autoria própria (2014) 
Vale ressaltar que algumas não são utilizadas na produção de todos os produtos, como por exemplo, a tijoleira, que é utilizada somente no processo de produção do tijolo comum branco. Já as prensas são usadas somente em telhas brancas. Em relação as horas/máquinas, o horário de trabalho das máquinas durante a semana é 8horas/dias e nos sábados 4horas/dia, com isso, foi calculada a média de horas diárias de funcionamento de cada máquinas, chegando a um valor médio de 8,72 horas por dia.

Realizado o cadastramento de todos os dados necessários através da funcionalidade "cadastro primário", passou-se a realizar a construção dos diagramas de montagem dos produtos através do sistema $\mathrm{POC}^{\circledR}$, apresentada a próxima seção.

\subsection{Diagramas de montagem}

No estudo realizado na indústria cerâmica, a funcionalidade "diagrama de montagem" do sistema $\mathrm{POC}^{\circledR}$ serviu para integrar, de uma forma gráfica, detalhada e interativa, a estrutura dos produtos (do inglês bill of materials) com o fluxo de processos produtivos. A partir dos diagramas de montagem, puderam ser registradas as quantidades de materiais, as horas de mão de obra e as horas de máquinas utilizadas no processo fabril de cada um dos 12 tipos de produtos cerâmicos considerados no estudo.

Conforme exposto na seção anterior, o processo produtivo é semelhante para os produtos, com exceção do tijolo comum branco que segue outra linha de produção e dos produtos que são prensados antes da secagem. As principais diferenças entre as operações são as quantidades de materiais, e o tempo de cada operação em termos de horas de mão de obra e/ou de horas de máquinas utilizadas. Para fins de exemplificação, as Figuras 15 e 16 apresentam os diagramas de montagem dos produtos telha plan branca e tijolo 09 x 19 x 24, respectivamente. 
Figura 15 - Diagrama de montagem do produto telha plan branca construído no sistema POC ${ }^{\circledR}$

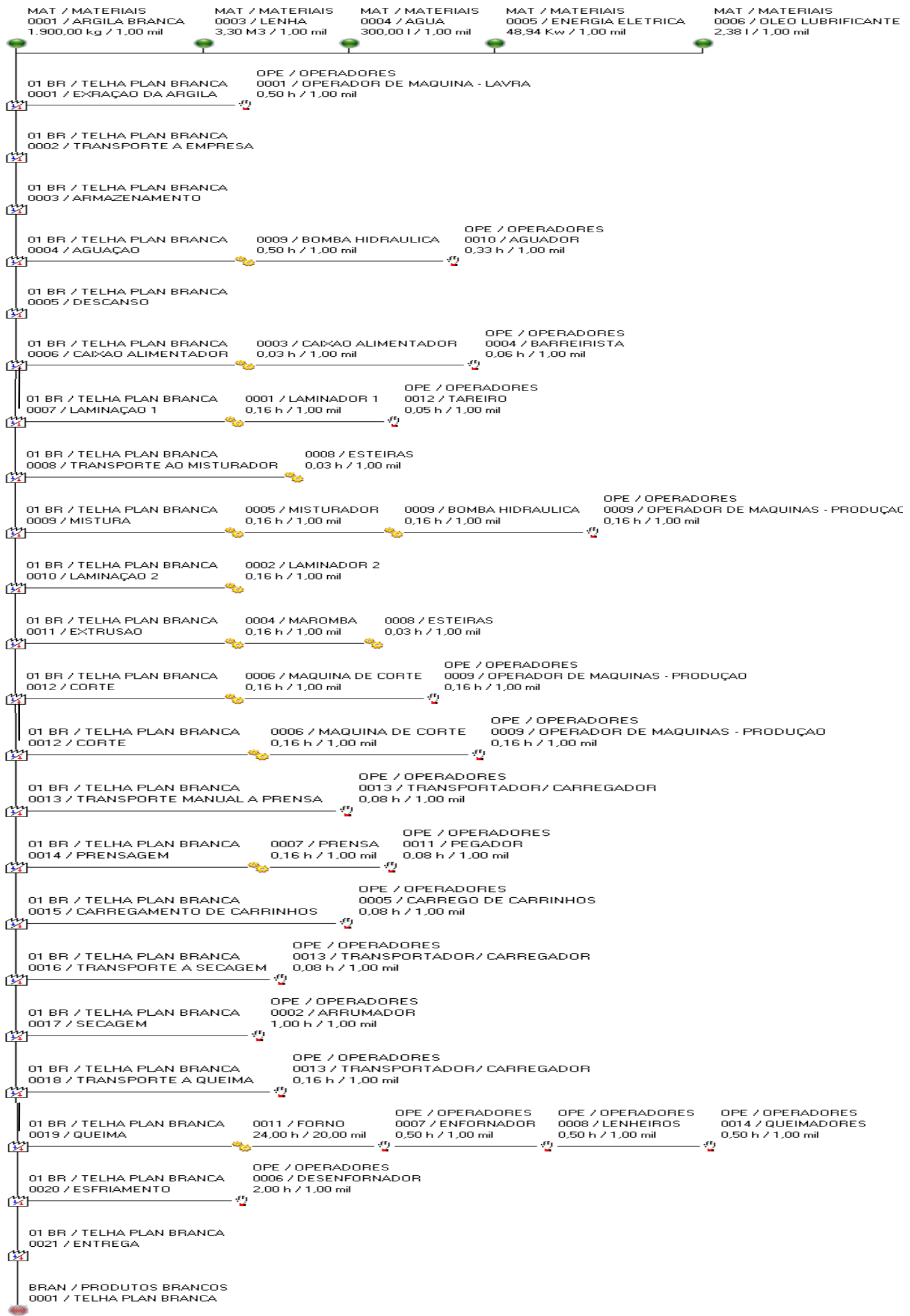

Fonte: Autoria própria (2014) 
Figura 16 - Diagrama de montagem do produto tijolo 09 x 19 x 24 construído no sistema POC ${ }^{\circledR}$

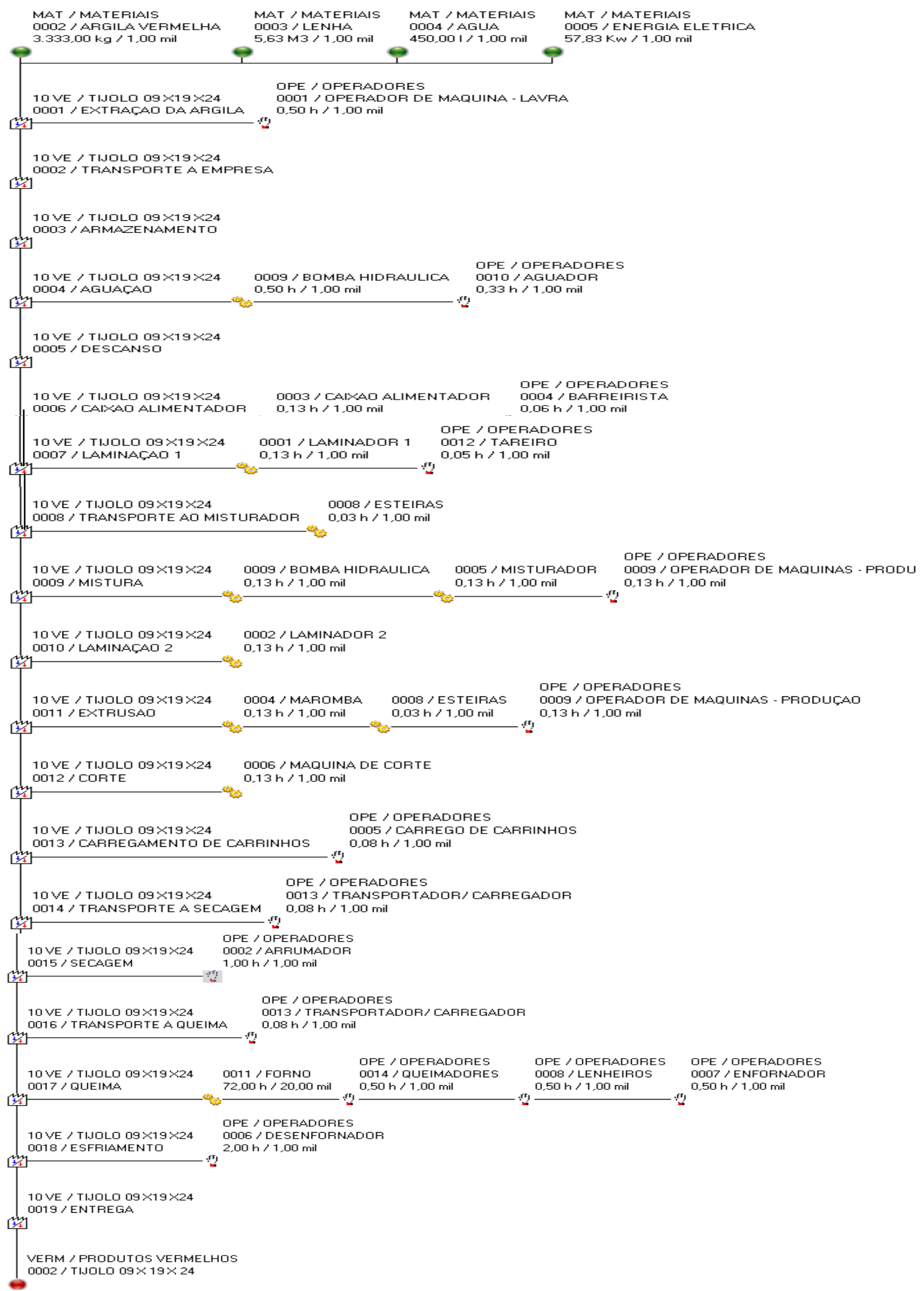

Fonte: Autoria própria (2014) 
Convém observar que as operações são ajustadas no diagrama em uma ordem decrescente, sendo os primeiros processos inseridos na parte superior e o restante seguindo a sequência do processo. Os recursos produtivos tais como os componentes materiais, as máquinas e a mão de obra são relacionados às operações. Convém observar que, quando qualquer um dos itens encontrados no diagrama é selecionado, é permitido registrar/alterar a quantidade necessária do recurso para a produção de cada produto para informar os coeficientes técnicos de utilização dos recursos produtivos. Destaca-se que as informações constantes nos diagramas de montagem foram essenciais para o cálculo dos custos unitários e das margens de contribuição dos produtos, como mostra a seção seguinte.

\subsection{Custos unitários e margens de contribuição}

Após o cadastro das informações inerentes às operações da empresa e a construção dos diagramas de montagem dos produtos, o sistema $\mathrm{POC}^{\circledR}$ possibilitou o cálculo e a visualização dos custos diretos de materiais, mão de obra e máquinas, das despesas variáveis de venda, incluindo impostos, e das margens de contribuição unitária e total (valor unitário multiplicado pela quantidade vendida) para cada um dos 12 tipos de produto fabricados pela empresa, apresentando-os em termos monetários e percentuais. A título de ilustração, as Figura 17 e 18 apresentam os custos unitários e as margens de contribuição dos produtos telha plan branca e tijolo 09 x 19 x 24, respectivamente. 
Figura17 - Custos unitários e margens de contribuição da telha plan branca obtidos através do sistema POC $^{\circledR}$

\begin{tabular}{|c|c|c|c|c|c|c|c|}
\hline \multicolumn{8}{|c|}{ B Custo unitário } \\
\hline $\begin{array}{l}\text { 量 } \\
\text { 皿 }\end{array}$ & $\begin{array}{l}\text { Gr } \\
\text { Có } \\
\text { De }\end{array}$ & $\begin{array}{l}\text { Grupo: BRAN PRODUTOS BRANCOS } \\
\text { Código: } 0001 \\
\text { Descriçāo: TELHA PLAN BRANCA }\end{array}$ & & & \multicolumn{3}{|c|}{$\begin{array}{l}\text { Estimativa: } 52,00 \mathrm{mil} / \mathrm{mês} \\
\text { Preço: } \mathrm{R} \$ \quad 650,00 \quad / \mathrm{mil} \\
\text { Código do Processo: } 1\end{array}$} \\
\hline \multicolumn{2}{|r|}{ Código } & Descriçāo & Coef.Tec. & Unit. Rs & Total R\$ & \% Parc. & \% Total \\
\hline \multicolumn{2}{|l|}{1} & Faturamento & & 707.07 & $36.767,64$ & & 100.00 \\
\hline \multirow{2}{*}{\multicolumn{2}{|c|}{$\begin{array}{l}1.1 \\
1.2\end{array}$}} & Preço & & 650,00 & $33.800,00$ & 91,93 & 100,00 \\
\hline & & Impostos por Fora & & 57.07 & 2.967 .64 & 8.07 & 8,78 \\
\hline \multicolumn{2}{|l|}{2} & Despesas Variáveis de Venda & & 57.07 & 2.967 .64 & & 8,07 \\
\hline \multirow{3}{*}{$\begin{array}{l}2.1 \\
2.2\end{array}$} & & Impostos por Dentro & & 0,00 & 0,00 & 0,00 & 0,00 \\
\hline & & Impostos por Fora & & 57,07 & 2.967 .64 & 100,00 & 8,78 \\
\hline & $\mathrm{IMP}$ & IMPOSTO 01 & $8,78 \%$ & 57,07 & $2.967,64$ & 100,00 & 0,00 \\
\hline \multicolumn{2}{|l|}{3} & Custos Variáveis de Produçāo & & 162,57 & $8.453,68$ & & 22,99 \\
\hline \multirow[t]{6}{*}{3.1} & & Custo de Materiais & & 113,39 & $5.896,30$ & 69,75 & 17.44 \\
\hline & 0003 & LENHA & $3,30 \mathrm{~m} 3$ & 49,50 & $2.574,00$ & 43,65 & 7.62 \\
\hline & 0001 & ARGILA BRANCA & $1.900,00 \mathrm{~kg}$ & 38,00 & $1.976,00$ & 33,51 & 5,85 \\
\hline & 0005 & ENERGIA ELETRICA & $48,94 \mathrm{Kw}$ & 18,11 & 941,61 & 15,97 & 2,79 \\
\hline & 0006 & OLEO LUBRIFICANTE & 2,381 & 7,78 & 404,70 & 6,86 & 1,20 \\
\hline & 0004 & AGUA & 300,001 & 0,00 & 0,00 & 0,00 & 0,00 \\
\hline \multirow{15}{*}{$\begin{array}{l}3.2 \\
3.3\end{array}$} & & Custos de Serviço de Terceiros & & 0,00 & 0,00 & 0,00 & 0,00 \\
\hline & & Custos de Mão-de-Obra & & 35,04 & $1.822,25$ & 21,56 & 5,39 \\
\hline & 0013 & TRANSPORTADOR/ CARREGADOR & $0,32 \mathrm{~h}$ & 8,76 & 455,27 & 24,98 & 1,35 \\
\hline & 0011 & PEGADOR & $0,08 \mathrm{~h}$ & 5,19 & 269,65 & 14,80 & 0,80 \\
\hline & 0005 & CARREGO DE CARRINHOS & $0,08 \mathrm{~h}$ & 3,12 & 162,45 & 8.92 & 0,48 \\
\hline & 0009 & OPERADOR DE MAQUINAS - PRODUÇAOO & $0,32 \mathrm{~h}$ & 2,53 & 131.67 & 7,23 & 0,39 \\
\hline & 0006 & DESENFORNADOR & $2,00 \mathrm{~h}$ & 2,13 & 110,54 & 6.07 & 0,33 \\
\hline & 0007 & ENFORNADOR & $0,50 \mathrm{~h}$ & 2,12 & 110,40 & 6,06 & 0,33 \\
\hline & 0008 & LENHEIROS & $0,50 \mathrm{~h}$ & 2,12 & 110,40 & 6,06 & 0,33 \\
\hline & 0014 & QUEIMADORES & $0,50 \mathrm{~h}$ & 2,12 & 110,40 & 6.06 & 0,33 \\
\hline & 0004 & BARREIRISTA & $0,06 \mathrm{~h}$ & 1,82 & 94,86 & 5.21 & 0,28 \\
\hline & 0001 & OPERADOR DE MAQUINA - LAVRA & $0,50 \mathrm{~h}$ & 1,61 & 83.59 & 4,59 & 0.25 \\
\hline & 0010 & A.GUADOR & $0,33 \mathrm{~h}$ & 1,54 & 80,26 & 4,40 & 0,24 \\
\hline & 0002 & ARRUMADOR & $1.00 \mathrm{~h}$ & 1.07 & 55,90 & 3.07 & 0,17 \\
\hline & 0012 & TAREIRO & $0,05 \mathrm{~h}$ & 0.90 & 46,86 & 2,57 & 0,14 \\
\hline \multirow[t]{11}{*}{3.4} & & Custos de Máquinas & & 14,14 & 735,13 & 8,70 & 2,17 \\
\hline & 0004 & MAROMBA & $0,16 \mathrm{~h}$ & 5,40 & 280,83 & 38,20 & 0,83 \\
\hline & 0011 & FORNO & $1,20 \mathrm{~h}$ & 2,23 & 116,06 & 15,79 & 0,34 \\
\hline & 0005 & MISTURADOR & $0.16 \mathrm{~h}$ & 2,16 & 112,13 & 15,25 & 0,33 \\
\hline & 0002 & LAMINADOR 2 & $0,16 \mathrm{~h}$ & 1.88 & 97,80 & 13,30 & 0.29 \\
\hline & 0001 & LAMINA.DOR 1 & $0.16 \mathrm{~h}$ & 1,14 & 59,29 & 8,06 & 0,18 \\
\hline & 0007 & PRENSA & $0.16 \mathrm{~h}$ & 0,76 & 39,38 & 5,36 & 0.12 \\
\hline & 0003 & CAIXAOOALIMENTADOR & $0,03 \mathrm{~h}$ & 0,30 & 15,51 & 2,11 & 0,05 \\
\hline & 0009 & BOMBA. HIDRAULICA & $0,66 \mathrm{~h}$ & 0.09 & 4,92 & 0.67 & 0,01 \\
\hline & 0006 & MAQUINA DE CORTE & $0,16 \mathrm{~h}$ & 0,09 & 4,67 & 0.64 & 0,01 \\
\hline & 0008 & ESTEIRAS & $0,06 \mathrm{~h}$ & 0,09 & 4,55 & 0.62 & 0.01 \\
\hline 4 & & Margem Real & & 487,43 & $25.346,32$ & & 68,94 \\
\hline
\end{tabular}

Fonte: Autoria própria (2014) 
Figura 18 - Custos unitários e margens de contribuição do tijolo 09 x 19 x 24branca obtidos através do sistema POC ${ }^{\circledR}$

\begin{tabular}{|c|c|c|c|c|c|c|c|}
\hline \multicolumn{8}{|c|}{ Q Custo unitário } \\
\hline $\begin{array}{l}\text { 量 } \\
\text { 昜 }\end{array}$ & $\begin{array}{l}\text { Gr } \\
\text { Có } \\
\text { De }\end{array}$ & $\begin{array}{l}\text { Grupo: VERM PRODUTOS VERMELHOS } \\
\text { Código:0002 } \\
\text { Descrição: TIJOLO } 09 \times 19 \times 24\end{array}$ & & & \multicolumn{3}{|c|}{$\begin{array}{l}\text { Estimativa: } 36,00 \quad \mathrm{mil} / \mathrm{mês} \\
\text { Preço: } \mathrm{R} \$ \quad 400,00 \quad / \mathrm{mil} \\
\text { Código do Processo: } 10\end{array}$} \\
\hline & Código & Descrição & Coef.Tec. & Unit. R\$ & Total R\$ & $\%$ Parc. & \% Total \\
\hline 1 & & Faturamento & & 435,12 & $15.664,32$ & & 100,00 \\
\hline 1.1 & & Preço & & 400,00 & $14.400,00$ & 91,93 & 100,00 \\
\hline 1.2 & & Impostos por Fora & & 35,12 & $1.264,32$ & 8,07 & 8.78 \\
\hline 2 & & Despesas Variáveis de Venda & & 35,12 & $1.264,32$ & & 8,07 \\
\hline 2.1 & & Impostos por Dentro & & 0,00 & 0,00 & 0,00 & 0,00 \\
\hline 2.2 & & Impostos por Fora & & 35,12 & $1.264,32$ & 100,00 & 8.78 \\
\hline & $\mathrm{IMP}$ & IMPOSTO 01 & $8.78 \%$ & 35,12 & $1.264,32$ & 100,00 & 0,00 \\
\hline 3 & & Custos Variáveis de Produção & & 180,97 & $6.515,09$ & & 41,59 \\
\hline 3.1 & & Custo de Materiais & & 139,18 & $5.010,38$ & 76,90 & 34,79 \\
\hline & 0003 & LENHA & $5,63 \mathrm{M} 3$ & 84,45 & $3.040,20$ & 60,68 & 21,11 \\
\hline & 0002 & ARGILA VERMELHA & $3.333,00 \mathrm{~kg}$ & 33,33 & $1.199,88$ & 23,95 & 8,33 \\
\hline & 0005 & ENERGIA ELETRICA & $57,83 \mathrm{Kw}$ & 21,40 & 770,30 & 15,37 & 5,35 \\
\hline & 0004 & AGUA & 450,001 & 0,00 & 0,00 & 0,00 & 0,00 \\
\hline 3.2 & & Custos de Serviço de Terceiros & & 0,00 & 0,00 & 0,00 & 0,00 \\
\hline 3.3 & & Custos de Mão-de-Obra & & 24,96 & 898,73 & 13,79 & 6,24 \\
\hline & 0013 & TRANSPORTADOR/ CARREGADOR & $0,16 \mathrm{~h}$ & 4,34 & 156,13 & 17,37 & 1,08 \\
\hline & 0005 & CARREGO DE CARRINHOS & $0,08 \mathrm{~h}$ & 3,12 & 112,47 & 12,51 & 0.78 \\
\hline & 0006 & DESENFORNADOR & $2,00 \mathrm{~h}$ & 2,13 & 76,53 & 8,52 & 0,53 \\
\hline & 0007 & ENFORNADOR & $0,50 \mathrm{~h}$ & 2,12 & 76,43 & 8,50 & 0,53 \\
\hline & 0008 & LENHEIROS & $0,50 \mathrm{~h}$ & 2,12 & 76,43 & 8,50 & 0,53 \\
\hline & 0014 & QUEIMADORES & $0,50 \mathrm{~h}$ & 2,12 & 76,43 & 8,50 & 0,53 \\
\hline & 0009 & OPERADOR DE MAQUUINAS - PRODUÇAO & $0,26 \mathrm{~h}$ & 2,06 & 74,06 & 8,24 & 0,51 \\
\hline & 0004 & BARREIRISTA & $0,06 \mathrm{~h}$ & 1.82 & 65,67 & 7,31 & 0,46 \\
\hline & 0001 & OPERADOR DE MAQUINA - LAVRA & $0,50 \mathrm{~h}$ & 1,61 & 57,87 & 6,44 & 0,40 \\
\hline & 0010 & AGUADOR & $0,33 \mathrm{~h}$ & 1,54 & 55,56 & 6,18 & 0,39 \\
\hline & 0002 & ARRIMMADOR & $1,00 \mathrm{~h}$ & 1,07 & 38,70 & 4,31 & 0,27 \\
\hline & 0012 & TAREIRO & $0,05 \mathrm{~h}$ & 0,90 & 32,44 & 3,61 & 0,23 \\
\hline 3.4 & & Custos de Máquinas & & 16,83 & 605,99 & 9,30 & 4,21 \\
\hline & 0011 & FORNO & $3,60 \mathrm{~h}$ & 6,70 & 241,04 & 39,78 & 1,67 \\
\hline & 0004 & MAROMBA & $0,13 \mathrm{~h}$ & 4,39 & 157,96 & 26,07 & 1,10 \\
\hline & 0005 & MISTURADOR & $0,13 \mathrm{~h}$ & 1.75 & 63,07 & 10,41 & 0,44 \\
\hline & 0002 & LAMINADOR 2 & $0,13 \mathrm{~h}$ & 1,53 & 55,01 & 9,08 & 0,38 \\
\hline & 0003 & CAIXAO ALIMENTADOR & $0,13 \mathrm{~h}$ & 1,29 & 46,52 & 7,68 & 0,32 \\
\hline & 0001 & LAMINADOR 1 & $0,13 \mathrm{~h}$ & 0,93 & 33,35 & 5,50 & 0,23 \\
\hline & 0009 & BOMBA HIDRALULICA & $0,63 \mathrm{~h}$ & 0,09 & 3.25 & 0,54 & 0,02 \\
\hline & 0008 & ESTEIRAS & $0,06 \mathrm{~h}$ & 0,09 & 3,15 & 0,52 & 0,02 \\
\hline & 0006 & MAQUINA DE CORTE & $0,13 \mathrm{~h}$ & 0,07 & 2,63 & 0,43 & 0,02 \\
\hline 4 & & Margem Real & & 219,03 & $7.884,91$ & & 50,34 \\
\hline
\end{tabular}

Fonte: Autoria própria (2014)

Convém destacar que o sistema $\mathrm{POC}^{\circledR}$ permite a realização de simulações do preço de venda dos produtos através da funcionalidade "orçamento". Essa funcionalidade permite relacionar o preço de venda com uma estimativa de margem de contribuição de produtos e pedidos específicos. A partir da explicitação de margens de contribuição mínima (inferior) e máxima (superior) 
desejadas, pode-se simular preços de venda e visualizar planilhas contendo custos e despesas relacionadas, além de gráficos de sensibilidade relacionando preços e margens de contribuição.

\subsection{Curva $\mathrm{ABC}$ de custos de materiais e de faturamento de produtos}

Como funcionalidade secundária, o sistema $\mathrm{POC}^{\circledR}$ possibilita a mensuração das quantidades agregadas dos materiais necessários para o cumprimento do plano de produção do período (ex: mês). Com base nos quantitativos físicos e dos custos de aquisição dos materiais, foi possível identificar o custo total mensal de cada tipo de material utilizado na empresa no período de análise, como mostra a Figura 19.

Figura19 - Necessidades e custos agregados de materiais obtidos através do sistema POC $^{\circledR}$

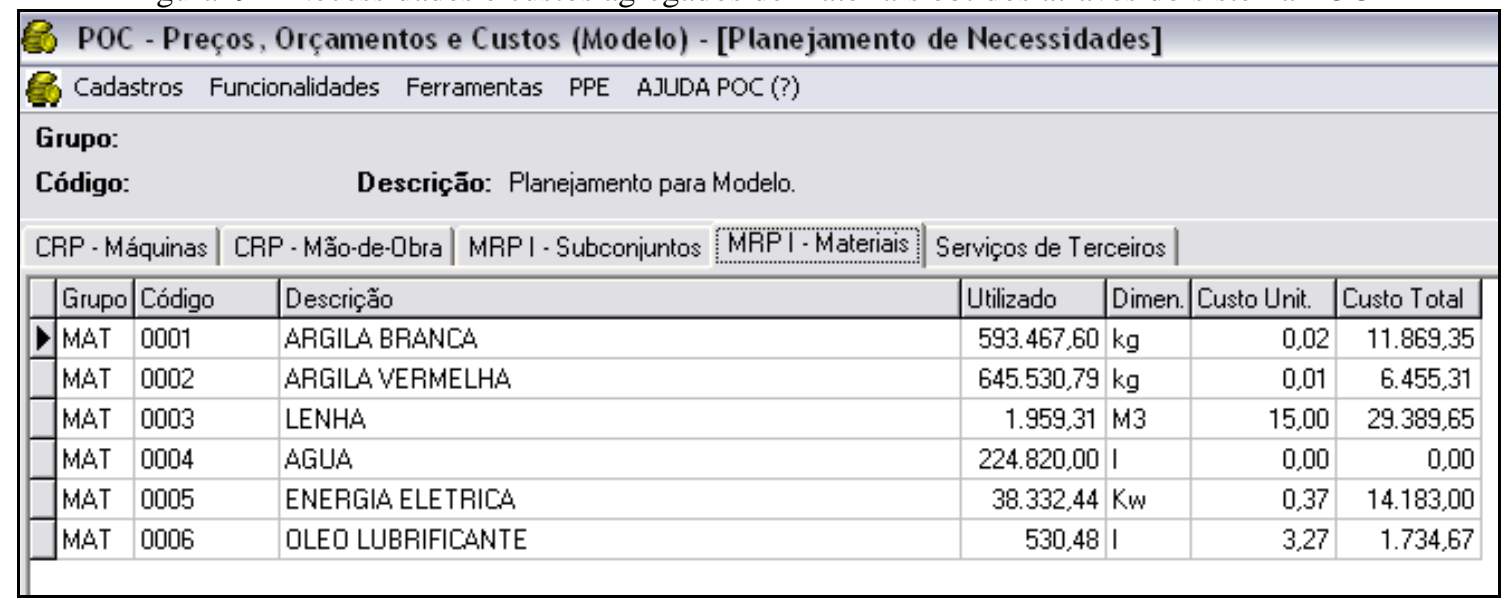

Fonte: Autoria própria (2014)

Com base nas informações de custos supracitadas, o sistema $\mathrm{POC}^{\circledR}$ possibilitou a construção e visualização da curva $\mathrm{ABC}$ de custos de materias (e utilidades) da empresa em estudo, tal como mostra a Figura 20.

Figura 20 - Curva ABC de custos de materiais obtida através do sistema POC $^{\circledR}$

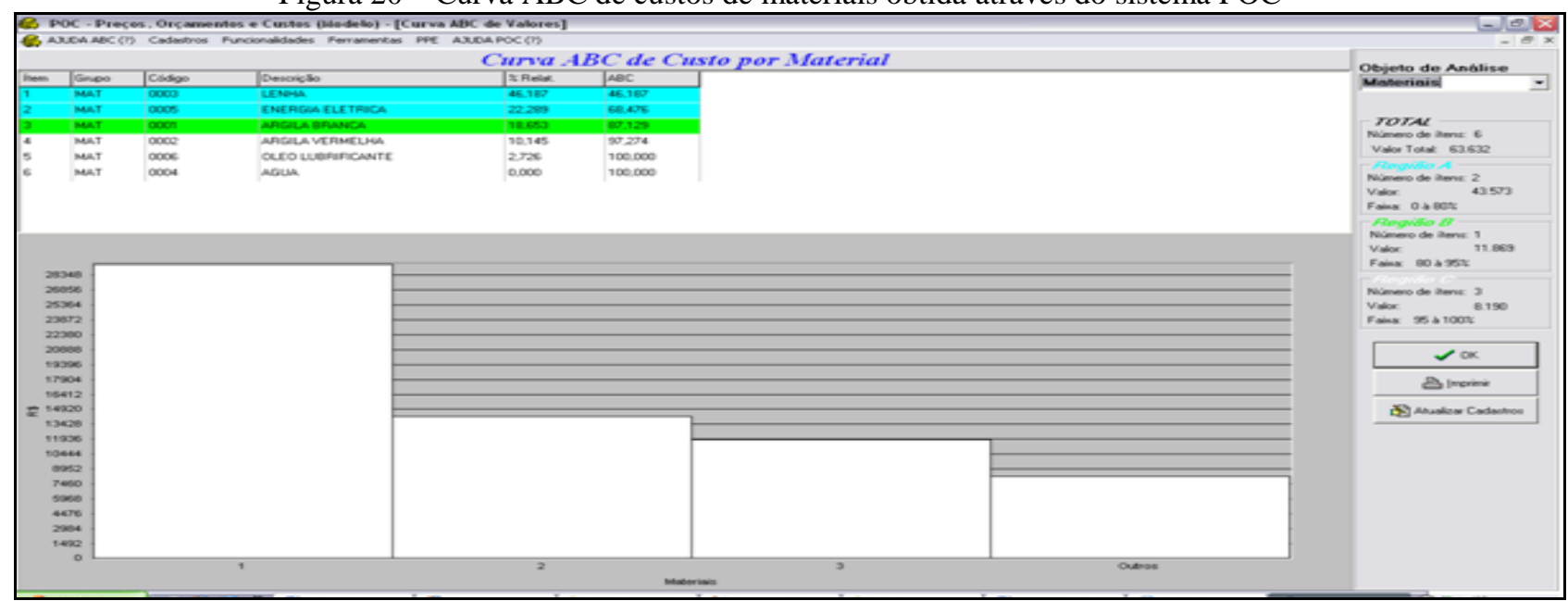

Fonte: Autoria própria (2014)

A curva $\mathrm{ABC}$ de custos de materiais e utilidades permitiu identificar que o material lenha representou $46,16 \%$ do custo total com materiais do período. Já os materiais/utilidades energia 
elétrica, argila branca, argila vermelha e óleo lubrificante representaram, respectivamente, 22,28\%, $18,65 \%, 10,14 \%$ e $2,76 \%$ do custo total de material. O recurso água praticamente não representou custo par aa operação. Desta forma, os gestores da organização estudada puderam visualizar os itens materiais que mais representaram custos para a empresa no período analisado.

Tomando como base informações relativas aos preços de venda e às quantidades vendidas mensais, o sistema $\mathrm{POC}^{\circledR}$ possibilitou a construção e visualização da curva $\mathrm{ABC}$ de faturamento dos produtos da empresa em estudo, tal como expõe a Figura 21.

Figura 21 - Curva ABC de faturamento de produtos obtida através do sistema POC $^{\circledR}$

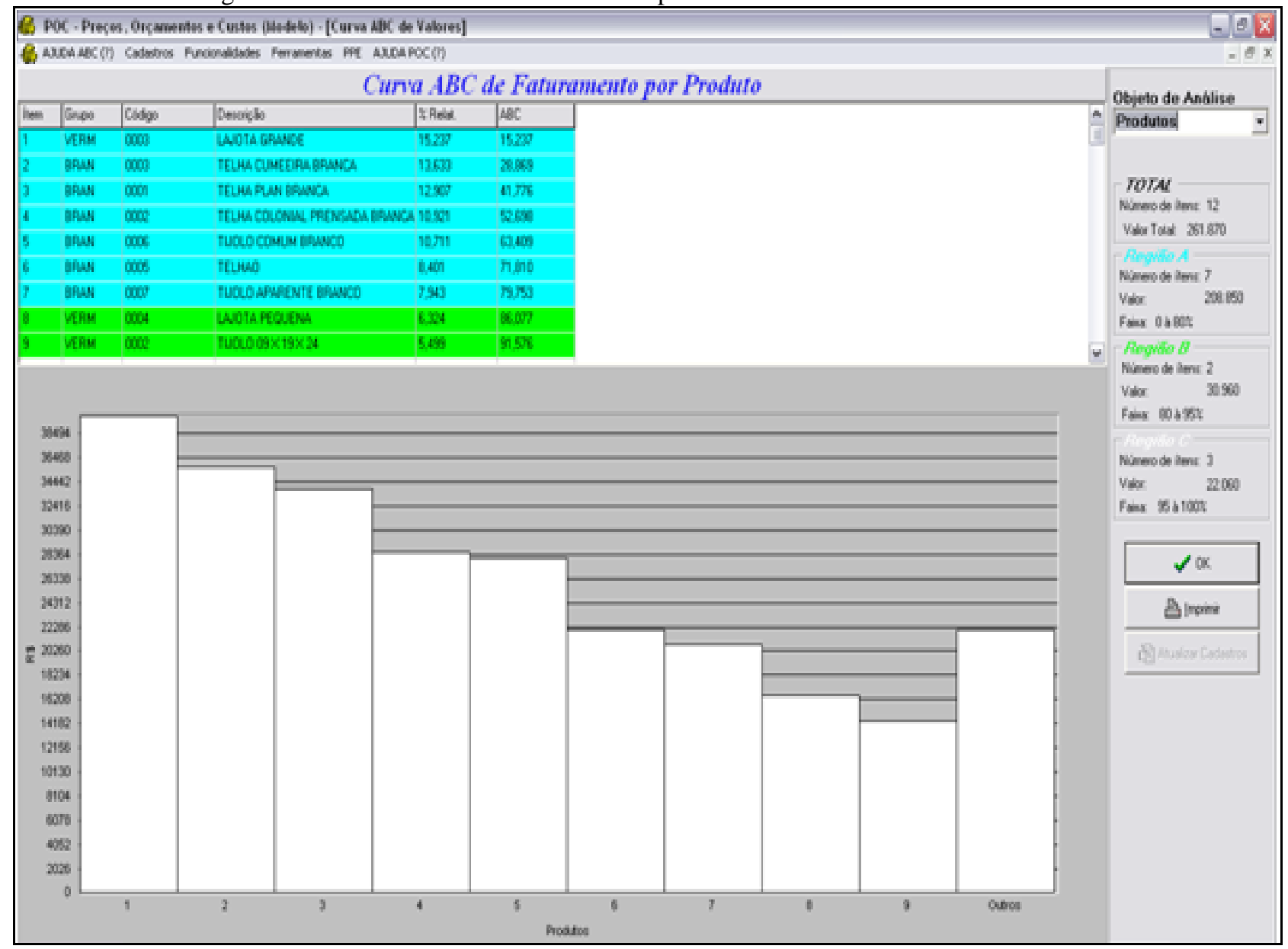

Fonte: Autoria própria (2014)

A curva $\mathrm{ABC}$ de faturamento de produtos permitiu identificar que há uma certa uniformidade de relevância dos produtos em termos de geração de faturamento para a empresa no período. Como destaques, podem ser citadas as vendas do produto lajota grande que representaram $15,27 \%$ do faturamento bruto da empresa no mês analisado. Por sua vez, o produto tijolo 09 x 19 x 24 representou apenas $5,49 \%$ do faturamento mensal da empresa. Com base nestas informações geradas pelos sistema $\mathrm{POC}^{\circledR}$, os gestores da empresa puderam visualizar os produtos finais que possuidores das maiores e das menores participações no faturamento bruto mensal. 


\subsection{Análise dos resultados econômicos e simulação de cenários}

O sistema $\mathrm{POC}^{\circledR}$ possibilitou a realização de análises econômicas de diferentes mix de produtos (tipos e quantidades de produtos produzidos e vendidos) tanto na forma de relatório, como também na forma gráfica. Inicialmente, a funcionalidade "mix de produtos" explicitou os resultados econômicos gerados por um mix de produtos mensal da empresa. Como o mix de produtos da empresa apresentava diferentes preços de venda, tipos e quantidades vendidas dos produtos, pôde-se identificar que cada produto possuia uma margem de contribuição específica. Nesse sentido, a Figura 22 apresenta o mix de produtos considerado na empresa estudada e explicita os custos, as despesas e as margens de contribuição (unitária e por tipo de produto) dos 12 produtos analisados.

\begin{tabular}{|c|c|c|c|c|c|c|c|c|c|c|c|c|c|c|}
\hline \multicolumn{15}{|l|}{ B Mix de Produtos } \\
\hline \multicolumn{15}{|l|}{ 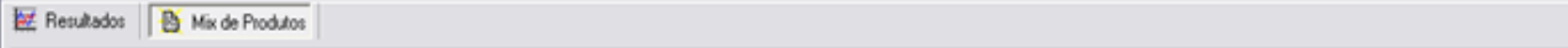 } \\
\hline Relatónio de Rentabilidade & \multicolumn{14}{|c|}{ gez SetUp B Impimi } \\
\hline \multicolumn{15}{|c|}{ 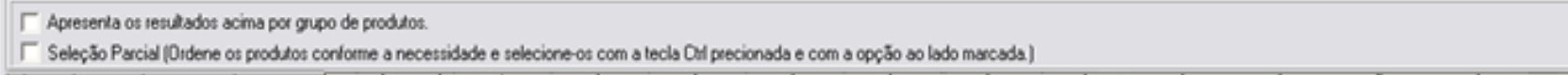 } \\
\hline Descisho & Qide & Dimen & Presco & Fotuariento & Fohs. $\%$ & $\mathrm{CV}$. & C.V.T. & CV.T. $*$ & D.V.V. & D.V.V.T. & D.V.V.T. $\%$ & M.C. & M.C.T. & M.C.T. $\%$ \\
\hline D TELHA PLAN BRANICA & 5200 & & 650,00 & 36.767 .64 & 13,06 & 162.57 & 8453.68 & 9.69 & 57.07 & 2967,64 & 13.06 & 487,43 & 25.346 .32 & $14 \pi 7$ \\
\hline TELHA COLONLAL PRENSADA BRANCA & 44,00 & & 650,00 & $31.111,08$ & 11.05 & 160,02 & 7.040 .74 & 8.07 & 57,07 & 2511.08 & 11,05 & 489.58 & 21.559 .26 & 1256 \\
\hline TELHA CUMEEIRA BRANCA & 51,00 & mal & 700,00 & 38834,46 & 13,79 & 207,36 & 10575,32 & 12.12 & 61.46 & $3.134,46$ & 13.79 & 492,64 & 25.124 .68 & 14,64 \\
\hline TELHINHA & 13.00 & mil & 450,00 & 6.363 .63 & 226 & 179,62 & 2335.05 & 288 & 39.51 & 513.53 & 2.26 & 270,38 & $3.514,95$ & 205 \\
\hline TELHAO & 40,00 & $\mathrm{md}$ & 550,00 & $23,931,60$ & 8.50 & 170,78 & 6831,03 & 7,83 & 48,29 & $1.931,60$ & 8.50 & 379,22 & $15.168,97$ & 884 \\
\hline TUOLO COMUM BRANCO & 51.00 & $\mathrm{mil}$ & 550,00 & 30.512 .79 & 1084 & 17728 & $9.041,30$ & 10,37 & 48.29 & 2452.79 & 10,84 & 372.72 & 19.008 .70 & 1108 \\
\hline TUOLO APAPENTE BRANCO & 3200 & mil & 650,00 & 22626,24 & 8,04 & 153,36 & 4907,51 & 5,63 & 57,07 & 1.886 .24 & 8,04 & 496,64 & 15898,49 & 9,26 \\
\hline CASQUILHO & 9.00 & $\mathrm{mil}$ & 435.50 & 4.273 .42 & 1.52 & 109.32 & $\$ 63.85$ & 1,13 & 38.32 & 344.92 & 1.52 & 327,18 & 2344.65 & 1.72 \\
\hline TEUHA COLONLAL VERMELHA & 38,00 & mil & 320,00 & $13.227,65$ & 4.70 & 104,93 & 3987,51 & 4,57 & 28,10 & $1.057,65$ & 4,70 & 215,07 & $8.172,49$ & 4.76 \\
\hline TNoto $09 \times 19 \times 24$ & 3.00 & mil & 400,00 & 15.654 .32 & 5.56 & 180.97 & 8.515 .09 & 7.47 & 35.12 & 1.254 .32 & 5.56 & 219.03 & 7.864 .91 & 4.80 \\
\hline LADTA GRANDE & 95,00 & mid & 360,00 & $37.200,76$ & 13,21 & 198,11 & 18820,78 & 21,58 & 31,61 & 3002,76 & 13,21 & 161,89 & $15.379,22$ & 8.56 \\
\hline LANOTA PEQUENA & 45,00 & mil & 420,00 & 21.016 .30 & 7.46 & 168,01 & 7.728 .46 & 8.96 & 36.88 & 1.596 .30 & 7.45 & 251.99 & 11.591 .54 & 6.76 \\
\hline
\end{tabular}

Fonte: Autoria própria (2014)

Onde:

Preço = Preço de Venda Líquido (deduz despesa variável/impostos sobre vendas - unitário do produto)

Faturamento = Receita Bruta (não deduz despesa variável/impostos sobre vendas - por tipo de produto)

C.V. = Custo Variável (unitário do produto)

C.V.T. $=$ Custo Variável Total (por tipo de produto)

C.V.T.\% = Custo Variável Total Percentual (por tipo de produto; somatório $=100 \%$ )

D.V.V. = Despesa Variável de Vendas (unitária do produto)

D.V.V.T. = Despesa Variável de Vendas Total (por tipo de produto)

D.V.V.T.\% = Despesa Variável de Vendas Total Percentual (por tipo de produto; somatório $=100 \%$ )

M.C. = Margem de Contribuição Unitária

M.C.T. $=$ Margem de Contribuição Total (por tipo de produto)

M.C.T. $\%=$ Margem de Contribuição Total Percentual (por tipo de produto; somatório $=100 \%$ )

De forma complementar, a Figura 23 apresenta graficamente e de forma decrescente as margens de contribuição unitárias e as margens de contribuição total, sendo comparadas, respectivamente, aos preços de venda brutos e aos faturamentos brutos de cada tipo de produto. 
Figura 23 - Margens de contribuição comparadas dos produtos

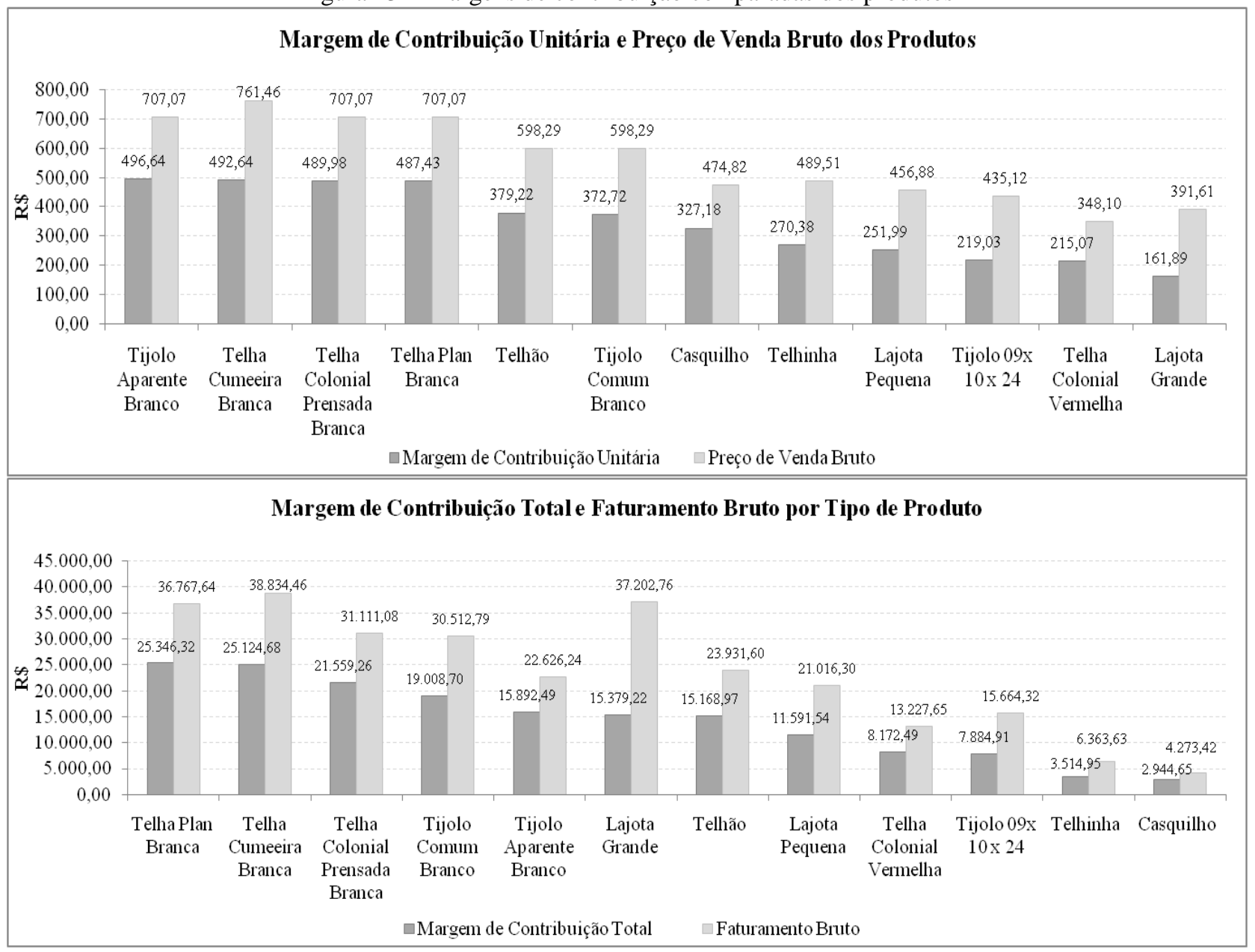

Fonte: Autoria própria (2014)

Com base nos resultados obtidos com o mix de produtos originalmente definido, os gestores da empresa puderam se certificar de que todos os produtos analisados eram lucrativos na medida em que apresentaram margens de contribuição positivas, ou seja, as respectivas receitas geradas foram capazes de cobrir todos os gastos diretamente relacioandos à cada produto. Ainda, os resultados explicitaram quais produtos geraram as maiores e as menores margens de contribuição para a empresa, tanto em termos individuais, como também em considerando as quantidades vendidas de cada tipo de produto.

Foi observado que, apesar de a margem de contribuição unitária do produto Tijolo Aparente Branco ter sido a maior ( $\mathrm{R} \$ 496,64)$, este tipo de produto não foi o que mais contribuiu para o pagamento de gastos fixos e geração de lucro para a empresa, visto que a margem de contribuição total apresentada foi a quinta maior $(\mathrm{R} \$ 15.892,49)$. Por sua vez, a despeito de o produto Lajota Grande apresentar a menor margem de contribuição unitária ( $\mathrm{R} \$ 161,89)$, este tipo de produto conseguiu obter a sexta maior margem de contribuição total ao se considerar a quantidade de produtos. Nesse sentido, vale destacar a importância de se considerar o volume de vendas na modelagem econômica de operações. 
Ainda, pôde-se visualizar a capacidade de geração de margem de contribuição que cada produto apresentou com relação ao preço de venda bruto. Nos extremos, por exemplo, calculou-se que o produto Tijolo Aparente Branco apresentou uma margem de contribuição percentual de $70,24 \%$ com relação ao preço de venda bruto ( $\mathrm{R} \$ 496,64$ divididos por $\mathrm{R} \$ 707,07$ ) e o produto Lajota Grande, por sua vez, apresentou uma margem de contribuição percentual de 41,34\% com relação ao preço de venda bruto ( $\mathrm{R}$ \$ 161,69 divididos por $\mathrm{R} \$ 391,61)$. Ressalta-se que, com exceção deste último, todos os tipos de produtos apresentaram margem de contribuição percentual com relação ao preço de venda bruto maior que 50\%, o que evidenciou aos gestores que, em geral, os produtos da empresa apresentam alta lucratividade. Outro ponto a destacar foi o fato de o produto Lajota Grande ter apresentado o segundo maior faturamento bruto e somente a sexta maior maior margem de contribuição total, o que evidenciou aos gestores da empresa que nem sempre os produtos com maiores volumes de vendas apresentam os melhores resultados econômicos.

$\mathrm{Na}$ sequência da modelagem econômica, foi utilizada a funcionalidade "resultados" do sistema POC $^{\circledR}$ para gerar um gráfico com a curva de faturamento, a curva de custos e despesas fixos, a curva de custos e despesas variáveis e a curva de custos e despesas totais do período, a partir dos quais se visualizou o ponto de equilíbrio contábil da empresa em termos de faturamento. Além disso, o sistema $\mathrm{POC}^{\circledR}$ forneceu o resultado econômico em termos de lucro do período para o mix de produtos em análise, como mostra a Figura 24.

Figura 24 - Ponto de equilíbrio e lucro mensais da empresa obtidos através do sistema POC ${ }^{\circledR}$

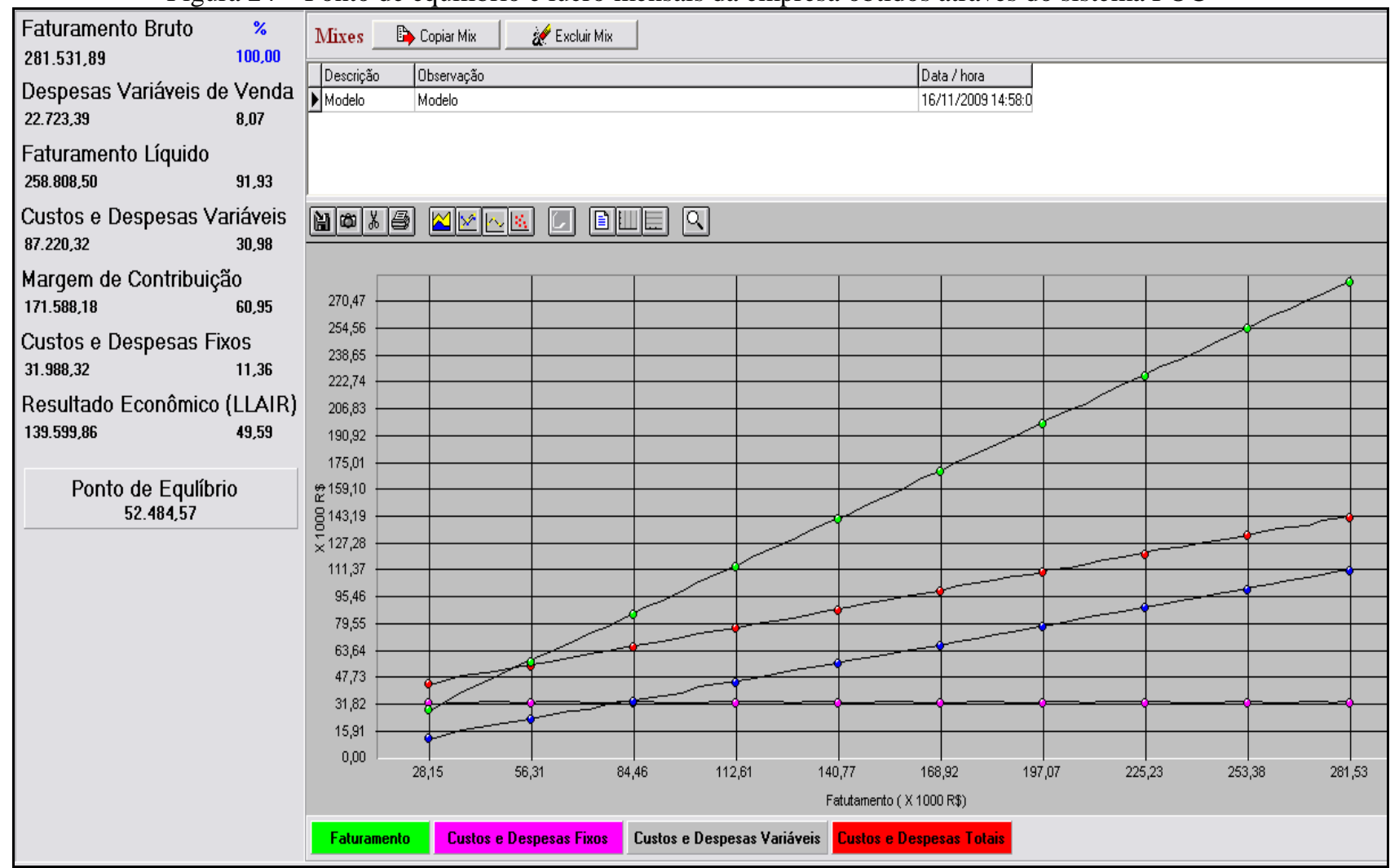

Fonte: Autoria própria (2014) 
Baseando-se nos resultados gerados, pôde-se visualizar que, para a empresa começar ter lucro, seria necessário um faturamento bruto de $\mathrm{R} \$ 59.056,08$ no período em questão. De fato, o faturamento mensal projetado para o mix de produtos analisado $(\mathrm{R} \$ 281.531,89)$ foi bem superior ao faturamento necessário para que a empresa atingisse o ponto de equilíbrio contábil. Ainda, foram obtidos um lucro mensal de $\mathrm{R} \$ 139.599 .86$ e uma lucratividade de 49,59\% para a empresa no mês em estudo. Como a organização analisada é optante pelo regime de tributação Simples Nacional, o resultado econômico em questão foi o lucro líquido mensal, uma vez que os impostos incidentes sobre renda da empresa foram debitados diretamente do faturamento bruto.

Convém observar que a funcionalidade "setup" do sistema $\operatorname{POC}^{\circledR}$ permite a definição de outros mix de produtos e de outros preços de venda para, a partir daí, os gestores poderem simular e analisar os resultados econômicos (individuais por produto e global da empresa) resultantes da operação estudada em termos de margens de contribuição, ponto de equilíbrio e lucro. Nesse sentido, a análise do mix de produtos permite aos gestores da empresa estudada a realização de simulações futuras de diferentes resultados econômicos consequentes, por exemplo, da necessidade de aumentar ou reduzir a quantidade produzida; aumentar ou diminuir o preço de venda dos produtos; ou até mesmo incluir ou excluir algum tipo de produto do portfólio da empresa. Ressaltase que o objetivo deste exercício final é explicitar a capacidade de realização de simulações proporcionada pelo sistema $\mathrm{POC}^{\circledR}$ para auxiliar a tomada de decisão.

\section{Considerações Finais}

Com base nos resultados obtidos através da aplicação do sistema POC ${ }^{\circledR}$, pôde-se verificar, na prática, a utilidade do referido sistema e suas potencialidade para a indústria cerâmica estudada. A aplicação das funcionalidades do $\mathrm{POC}^{\circledR}$ redirecionou a gestão de custos dentro da organização ao possibilitar a estruturação e o fornecimento de informações acuradas que serviram como base fundamentada para, na perspectiva econômica, modelar os processos de negócios e apoiar a tomada de decisões dos gestores da empresa. Desta forma, a operacionalização do sistema POC $^{\circledR}$ possibilitou a modelagem econômica das operações da empresa para que, a partir disso, os gestores tomassem ciência dos custos dos processos, dos materiais, da mão de obra e dos produtos, além das margens de contribuição dos produtos. Portanto, o objetivo do estudo foi atingido.

O levantamento dos dados referentes aos processos produtivos e a estruturação dos diagramas de montagem dos produtos serviram como base para operacionalização do sistema POC $^{\circledR}$. A curva ABC obtida sugeriu a necessidade de um melhor controle de estoque de materiais, especialmente, no que tange ao insumo lenha. Ainda, a curva ABC possibilitou a identificação dos produtos com maiores receitas para a empresa, com destaque ao produto lajota grande. No caso dos 
fatores de produção tais como mão de obra e equipamentos, identificaram-se aqueles que apresentaram maiores custos para o sistema produtivo analisado.

O cálculo das margens de contribuição unitária e total por tipo de produto possibilitou a compreensão dos itens que mais geravam lucratividade para a empresa. Com base nas informações estruturadas no sistema POC, foram propostas ações gerenciais aos gestores da empresa no tocante à priorização de produtos que apresentaram os melhores resultados econômicos e à redução de custos de produção dos produtos com menores margens de contribuição.

É importante indicar como limitação que os resultados deste trabalho não podem ser generalizados para toda a população de indústrias de cerâmica, uma vez que as informações apresentadas são singulares e restritas à organização analisada no estudo. Mesmo se mostrando útil, o uso do sistema $\mathrm{POC}^{\circledR}$ demanda esforço e organização das informações empresariais, pois é necessária a utilização de uma grande quantidade de dados que dificilmente estão estruturados e com fácil acesso a priori, principalmente em termos de pequenas e médias empresas com baixo nível de profissionalização da gestão. Ainda, para a correta operacionalização do referido sistema, foram necessários conhecimentos especializados sobre contabilidade gerencial, na interface com a gestão de operações, sobre o processo produtivo a ser estudado e sobre a realização da classificação de gastos de operações industriais.

Como recomendação para trabalhos futuros, sugere-se a utilização de outras funcionalidades e possibilidades de análise do sistema $\mathrm{POC}^{\circledR}$, tais como: análise econômica de terceirizações de subconjuntos, atividades e produtos; análise econômica de substituição e alteração de recursos produtivos; e construção do diagrama "de-para" que serve como base de análise para melhoria do arranjo físico fabril. Ainda, indica-se a realização de simulações de preços de pedidos ou lotes de produtos através da funcionalidade "orçamento". Dessa forma, será possível verificar se um pedido é ou não viável econômicamente e simular o aumento ou a diminuição da produção considerando o ponto de equilíbrio e o mix de produtos. Ainda, para se ter uma análise mais acurada do impacto da elevação dos preços, recomenda-se como estudo futuro a mensuração da elasticidade-preço da demanda dos produtos.

Como outra possibilidade de estudo futuro, indica-se a análise de viabilidade da ampliação do mix de produtos e da expansão futura de capacidade. O estudo pode contemplar a aquisição de novas máquinas e a contratação de novos funcionários, simulando os custos e as receitas incrementais que iriam ser gerados à empresa. Essa nova modelagem econômica pode ser realizada com base em informações estruturadas através do software $\mathrm{POC}^{\circledR}$.

Finalmente, almeja-se que os gestores vejam a importância da modelagem econômica para se ter o real conhecimento acerca do que é gasto na empresa e das margens de contribuição dos produtos para que, a partir dessas informações, possam tomar decisões fundamentadas em fatos e 
dados estruturados para garantir a sustentabilidade econômica da organização. Ainda, almeja-se que o estudo apresentado sirva como base para trabalhos futuros sobre modelagem econômica em organizações que operem com sistemas de produção de cerâmica vermelha.

\section{Abstract}

Currently, in order to remain competitive and aid decision making, an organization must use technologies compatible with the economic management needs of their business processes. In this context, the paper presents the use of decision support system POC ${ }^{\circledR}$ - Industrial Prices, Costs and Budgets - to assist modeling and managerial analysis of costs and prices in a ceramic manufacturer for economic decision-making. To fulfill the objective, the paper is methodologically worked from a literature research and a field survey in which information are collected and analyzed about the production process and the costs and prices structure of the industry studied. As main results, the POC $^{\circledR}$ system has enabled the operation economic modeling in terms of (i) construction of products assembly diagrams and the $\mathrm{ABC}$ curves on materials costs and products revenues, (ii) determining costs, expenses, prices and contribution margins of products, and profit of the factory studied. Finally, it is concluded that the use of decision support system POC ${ }^{\circledR}$ proved be useful to perform operations economic modeling and assist managers in the ceramic factory addressed in the study.

Key-words: operations economic modeling; decision support system $\mathrm{POC}^{\circledR}$; cost management and pricing; ceramics industry.

\section{Referências}

ABC - ASSOCIAÇÃO BRASILEIRA DE CERÂMICA. Informações técnicas - processos de fabricação. Disponível em: 〈http://www.abceram.org.br/site/index.php?area=4\&submenu=50>. Acesso em: 10 jun. 2014.

ANICER - ASSOCIAÇÃO NACIONAL DA INDÚSTRIA CERÂMICA. Diagnóstico das indústrias de cerâmica vermelha do estado do Rio de Janeiro. Disponível em:

$<$ http://www.anicer.com.br/index.asp?pg=institucional.asp\&secao=3\&categoria=57\&selMenu=4〉. Acesso em: 04 jun. 2014.

ATKINSON, A. A., BANKER, R. D., KAPLAN, R.S., YOUNG, S. M. Management accounting. $2^{\text {nd }}$ ed. PrenticeHall Inc., London, 1997.

BORNIA, A. C. Análise gerencial de custos: aplicação em empresas modernas. $3^{\text {a }}$ ed. São Paulo: Bookman, 2010.

BRUNI, A. L.; FAMÁ, R. Gestão de custo e formação de preços. São Paulo: Atlas, 2009.

BRUNSTEIN, I. Economia de empresas: gestão econômica de negócios. São Paulo: Atlas, 2005.

CHATFIELD, M. The origins of costs accounting. Management Accounting, v. 52, n. 12, 1971.

COSTA, R. P.; FERREIRA, H. A. S.; SARAIVA JR., A. F. Preços, orçamentos e custos industriais. Rio de Janeiro: Campus-Elsevier, 2010.

FREZATTI, F.; AGUIAR, A. B.; GUERREIRO, R. Diferenciações entre a contabilidade financeira e a contabilidade gerencial: uma pesquisa empírica a partir de pesquisadores de vários países. Revista de Contabilidade e Finanças da USP, n. 44, p. 9-22. 2007.

GARRISON, R. H.; NOREEN, E. W.; BREWER, P. C. Managerial accounting. $11^{\text {th }}$ ed. McGraw-Hill, New York, 2006.

GIL, A. C. Como elaborar projeto de pesquisa. $4^{a}$ ed. São Paulo: Atlas, 2002.

HANSEN, D. R.; MOWEN, M. M. Cost management. $2^{\text {nd }}$ ed. Cincinnati: South-Western College Publications, 1997. 
HORNGREN, C. T.; FOSTER, G.; DATAR, S. M. Cost accounting: a managerial emphasis. Prentice-Hall, Upper Saddle River, 2006.

IMA - INSTITUTE OF MANAGEMENT ACCOUNTING. Definition of management accounting, 2008. Disponível em: <http://www.imanet.org/pdf/definition.pdf>. Acesso em: 11 ago. 2014.

MARCONI, M. A.; LAKATOS, E. M. Metodologia científica. 6 $6^{\text {a }}$ ed. São Paulo: Atlas, 2011.

MARTINS, E. Contabilidade de custos. 10ª ed. São Paulo: Atlas, 2010.

PADOVEZE, C. L. Curso básico gerencial de custos. 2ª ed. São Paulo: Pioneira Thomson Learning, 2006.

SARAIVA JR., A. F.; COSTA, R. P.; FERREIRA, H. A. S. Using POC decision support system in operations management teaching. In: $24^{\text {th }}$ ANNUAL PRODUCTION AND OPERATIONS MANAGEMENT SOCIETY CONFERENCE. Anais... Denver, United States, POMS 2013.

SARAIVA JR., A. F.; TABOSA; C. M.; COSTA, R. P. Simulação de Monte Carlo aplicada à análise econômica de pedido. Produção, v. 21, n. 1, p. 149 - 164, 2011. crossref

SEBRAE-RN - SERVIÇO BRASILEIRO DE APOIO ÀS MICRO E PEQUENAS EMPRESAS .DO ESTADO DO RIO GRANDE DO NORTE. APL de Cerâmica Vermelha. Disponível em: <

http://portal.rn.sebrae.com.br/pagina.php?id=156 >. Acesso em: 25 jul. 2014.

SEBRAE-SP - SERVIÇO BRASILEIRO DE APOIO ÀS MICRO E PEQUENAS EMPRESAS .DO ESTADO DE SÃO PAULO. Causa mortis: o sucesso e o fracasso das empresas nos primeiros 5 anos de vida. Disponível em: <http://www.sebraesp.com.br/arquivos_site/biblioteca/EstudosPesquisas/mortalidade/causa_mortis_2014.pdf>. Acesso em 14 ago. 2014

\section{Dados dos autores}

Nome completo: Rochelly Sirremes Pinto

Filiação institucional: Universidade Federal do Rio Grande do Norte - UFRN

Departamento de Ciências Sociais e Tecnológicas

Função ou cargo ocupado: Engenheira de Produção e Mestranda em Engenharia de Produção

Endereço completo para correspondência: Rua Antônio Farache, n. 503, Natal, Rio Grande do Norte, Brasil. CEP: 59010-020

Telefones para contato: (84) 91620023

e-mail: rochellykarillo@ hotmail.com

Nome completo: Abraão Freires Saraiva Júnior

Filiação institucional: Universidade Federal Ceará - UFC

Departamento de Engenharia de Produção

Função ou cargo ocupado: Professor e Vice-Coordenador do Curso de Graduação em Engenharia de Produção

Endereço completo para correspondência: Rua Coronel Mozart Gondim, n. 1400, ap. 202, Fortaleza, Ceará, Brasil. CEP: 60320-250

Telefones para contato: (85) 88246068 
e-mail: abraaofsjr@gmail.com

Nome completo: Fábio Roberto Abreu Junior

Filiação institucional: Universidade Federal do Semi-Árido - UFERSA

Departamento de Ciências Sociais e Tecnológicas

Função ou cargo ocupado: Engenheiro de Produção

Endereço completo para correspondência:

UFERSA, BR 110, km 47, Bairro: Costa e Silva, Mossoró, Rio Grande do Norte, Brasil, CEP: 59625-900

Telefones para contato: (84) 96687231

e-mail: $\underline{\text { f_jwnyor@hotmail.com }}$

Nome completo: Raimundo Alberto Rêgo Junior

Filiação institucional: Universidade Federal do Semi-Árido - UFERSA

Departamento de Ciências Sociais e Tecnológicas

Função ou cargo ocupado: Engenheiro de Produção

Endereço completo para correspondência: Rua: Hemetério Fernandes, n. 197, Bairro: Centro, Pau dos Ferros, Rio Grande do Norte, Brasil, CEP: 59900-000

Telefones para contato: (84) 88390297

e-mail: albertojuniorpdf@hotmail.com

Nome completo: Reinaldo Pacheco da Costa

Filiação institucional: Escola Politécnica da Universidade de São Paulo - POLI USP

Departamento de Engenharia de Produção

Função ou cargo ocupado: Professor Dr.

Endereço completo para correspondência: Av. Prof. Almeida Prado, travessa 2, $\mathrm{n}^{\mathrm{o}}$ 128, Cidade Universitária, CEP: 05508-070. São Paulo-SP, Brasil.

Telefones para contato: (11) 30915399 ramal 408

e-mail: rpcosta@usp.br

Submetido em: 11/09/2014

Aceito em: 17/12/2014 